\title{
Detection and characterization of two ATP-dependent conformational changes in proteolytically inactive Escherichia coli Lon mutants by stopped flow kinetic techniques
}

\author{
Jessica Patterson-Ward, Jon Huang, and Irene Lee \\ Department of Chemistry, Case Western Reserve University, Cleveland, OH 44106
}

\begin{abstract}
Lon is an ATP dependent serine protease responsible for degrading denatured, oxidatively damaged and certain regulatory proteins in the cell. In this study we exploited the fluorescence properties of a dansylated peptide substrate (S4) and the intrinsic Trp residues in Lon to monitor peptide interacting with the enzyme. We generated two proteolytically inactive Lon mutants, S679A and S679W, where the active site serine is mutated to an Ala and Trp residue, respectively. Stopped-flow fluorescence spectroscopy was used to identify key enzyme intermediates generated along the reaction pathway prior to peptide hydrolysis. A two-step peptide binding event is detected in both mutants, where a conformational change occurs after a rapid equilibrium peptide binding step. The $\mathrm{K}_{\mathrm{d}}$ for the initial peptide binding step determined by kinetic and equilibrium binding techniques is approximately 164 and 38, respectively. The rate constants for the conformational change detected in the S679A and S679W Lon mutants are $0.74 \pm 0.10 \mathrm{~s}^{-1}$ and $0.57 \pm 0.10 \mathrm{~s}^{-1}$, respectively. These values are comparable to the lag rate constant determined for peptide hydrolysis $\left(\mathrm{k}_{\mathrm{lag}} \sim 1 \mathrm{~s}^{-1}\right)$ [Vineyard, D, et al. (2005) Biochemistry 45, 4602-4610]. Replacement of the active site Ser with Trp (S679W) allows for the detection of an ATP-dependent conformational change within the proteolytic site. The rate constant for this conformational change is $7.6 \pm 1.0 \mathrm{~s}^{-1}$, and is essentially identical to the burst rate constant determined for ATP hydrolysis under comparable reaction conditions. Collectively, these kinetic data support a mechanism by which the binding of ATP to an allosteric site on Lon activates the proteolytic site. In this model, the energy derived from the binding of ATP, minimally supports peptide cleavage by allowing peptide substrate access to the proteolytic site. However, the kinetics of peptide cleavage are enhanced by the hydrolysis of ATP.
\end{abstract}

Lon, also known as protease La, is a homo-oligomeric ATP dependent serine protease localized in the cytosol of prokaryotes and the mitochondria of eukaryotes (3-9). As a member of the $\mathrm{AAA}+$ (ATPases associated with a variety of cellular activities) family of proteases, Lon's primary function is to degrade denatured, oxidatively damaged and certain regulatory proteins in the cell. Lon has been shown to be important for Salmonella enterica infection in mice $(10,11)$ as well as a stress-response protease necessary for virulence in Brucella abortus (12). In mammalian cells, Lon is found in the mitochondria and down regulation of Lon disrupts mitochondrial function and causes cell death (13).

Each enzyme subunit of Lon consists of an N-terminal domain with unknown function, an ATPase domain, an SSD (substrate sensor and discriminatory) domain and a protease domain $(14,15)$. According to the crystal structure of the protease domain (16) and electron microscopy studies (17), Escherichia coli (E. coli) Lon is a hexamer consisting of six identical subunits that adopt a self-compartmentalized structure found in many ATP dependent proteases. 
Mechanistic characterization of Lon from E. coli reveals that the protease utilizes a Ser-Lys dyad (S679 and K722) to catalyze peptide bond hydrolysis (16). Despite the presence of this catalytic dyad, the hydrolytic activity of Lon remains dormant until the enzyme binds and hydrolyzes ATP at a site distal from the protease domain. In fact, optimal peptide bond cleavage is accompanied by ATP hydrolysis. However, the ATPase and peptidase activities of Lon are not stoichiometrically linked, as certain non-hydrolyzable ATP analogs such as AMPPNP can activate the degradation of unstructured protein and peptide substrates $(1,2,18)$. Furthermore, substitution of the proteolytic site Ser with Ala affects only the protease activity without influencing the intrinsic or the protein-stimulated ATPase activity of the enzyme (19).

Other ATP-dependent proteases that belong to the same family as Lon also utilize ATP hydrolysis to promote the translocation of unfolded polypeptide substrates to the proteolytic active site. It is generally believed that the translocation of polypeptides constitutes the ratelimiting step of the peptide hydrolysis reaction (20-22). Although it is plausible that Lon utilizes a similar mechanism in mediating peptide bond cleavage, this has not been unambiguously demonstrated. The detection of a rate-limiting step in the binding interaction between Lon and the peptide substrate in the presence of ATP will provide support for the existence of the proposed peptide translocation step.

To elucidate the timing of ATP hydrolysis with activation of peptide bond cleavage by $E$. coli Lon, we have previously generated a synthetic peptide (designated S1) which contains residues $89-98$ of the $\lambda \mathrm{N}$ protein which is an endogenous protein substrate of $E$. coli Lon (1, 2 ). We demonstrated that the degradation of $\mathrm{S} 1$ exhibits the same ATP-dependency and cleavage specificity as the full-length $\lambda \mathrm{N}(1,2)$. Using pre-steady-state kinetic techniques, we also demonstrated that ATP hydrolysis occurs prior to peptide bond cleavage since a burst in ATPase activity is coupled with a lag in proteolysis (23). Comparing the rate-constants of the two hydrolytic reactions suggest that the lag phase of peptide cleavage is dependent on the build up of an enzyme intermediate generated during and/or after ATP hydrolysis, which could be attributed to the existence of the proposed ATP-dependent peptide translocation step.

In this study, we probed the existence of an ATP-dependent peptide translocation step using a similar technique used by Epps et al., and Fattori et al., to monitor the kinetics of peptideprotein interactions $(24,25)$. We employed pre-steady-state kinetic techniques to monitor the dynamics of a dansylated peptide (designated S4) interacting with two proteolytically inactive E. coli Lon mutants, S679A and S679W. Upon binding to the target protein, the fluorescence signal associated with a dansylated peptide is indirectly enhanced by excitation of the intrinsic Trp residues located within the protease. These authors (Epps et al. and Fattori et al.) refer to this fluorescence technique as FRET (fluorescence resonance energy transfer) $(24,25)$.

Analysis of the fluorescence time courses allowed us to construct a kinetic model revealing the enzyme intermediates generated from the binding and hydrolysis of ATP in the presence of the S4 peptide. The proteolytically inactive mutant S679A contains the three intrinsic Trp residues found in wild type Lon (15) while S679W contains an additional Trp residue in place of the active site Ser. The kinetics of the S4 peptide binding to either Lon mutant in the presence of ATP was monitored by exciting the Trp residues at $290 \mathrm{~nm}$ and detecting the rates of dansyl fluorescence increase at $>450 \mathrm{~nm}$. Applying stopped flow kinetic techniques, we were able to detect two distinct conformational changes in either $E$. coli Lon mutant that are dependent on the presence of the S4 peptide and nucleotide binding (ATP or AMPPNP). The rate constant of this step agrees well with the lag rate constant of peptide hydrolysis that was determined previously (23). However, an additional conformational change is detected in S679W that is dependent only upon the presence of nucleotide. Collectively, these data support a mechanism by which ATP binding and hydrolysis allosterically activates the proteolytic site of Lon, and facilitates translocation of peptide substrates by inducing at least two distinct conformational changes within the enzyme complex. Furthermore, ATP hydrolysis offers an additional 
catalytic advantage in mediating peptide bond cleavage by facilitating the formation of the two conformational changes detected in this study.

\section{Materials and Methods}

\section{Materials}

ATP (adenosine triphosphate), ADP (adenosine diphosphate), AMPPNP (adenylyl 5imidodiphosphate), dansyl chloride, SBTI (soybean trypsin inhibitor), TPCK-treated Trypsin, $N$-2-hydroxyethylpiperazine- $N$ '-ethanesulphonic acid (HEPES) and polyethyleneiminecellulose (PEI-cellulose) TLC plates were purchased from Sigma and Fisher. All Fmocprotected amino acids, Fmoc-protected Lys Wang resin, Boc-anthranilamide (Abz), and $O$ benzotriazole- $N, N, N^{\prime}, N^{\prime}$-tetramethyluroniumhexafluorophosphate (HBTU) were purchased from Advanced ChemTech and EMD Biosciences. $\left[\alpha{ }^{32} \mathrm{P}\right]$ ATP was purchased from PerkinElmer Life Science. QuikChange Site-Directed Mutagenesis Kit was purchased from Statagene. Primers were purchased from Integrated DNA Technologies.

\section{General Methods}

Peptide synthesis and protein purification procedures were performed as described previously (1). All enzyme concentrations are reported as Lon monomer concentrations. All experiments were performed at $37^{\circ} \mathrm{C}$. All reagents are reported as final concentrations.

\section{Generation and Characterization of Lon mutants}

Two Lon mutants, S679A and S679W, were generated using the wild type E. coli Lon protease plasmid (pSG11, a generous gift from Alfred Goldberg, Harvard Medical School) and the QuikChange Site-Directed Mutagenesis Kit from Stratagene. The forward primer used to generate the S679A mutant (pJW028 plasmid) was 5'-

GCCGAAAGATGGTCCGGCTGCCGGTATTGC-3' and the reverse primer was 5'GCAATACCGGCAGCCGGACCATCTTTCGGC $-3^{\prime}$. The forward primer used to generate the S679W mutant (pJW015 plasmid) was 5'-AAAGATGGTCCATGGGCCGGTATTGCT-3' and the reverse primer was $5^{\prime}$-AGCAATAGGGGCCCATGGACCATCTTT- $3^{\prime}$. The sequence of pJW028 and pJW015 was verified by DNA sequencing. Both plasmids were transformed into the BL21 E. coli cell strain. S679A and S679W Lon was expressed and purified to homogeneity using the protocols described previously for the wild type enzyme (1). ATPase activity was measured using radiolabeled ATP as described previously $(26,27)$. MANT-ATP binding was measured using stopped-flow techniques as described previously (28).

\section{Fluorescence Emission Scans}

Emission spectra were collected on a Fluoromax 3 spectrofluorimeter (Horiba Group) with excitation of the Trp residues at $290 \mathrm{~nm}$. All assays were performed in microcuvettes (Hellma) with a 3-mm path length. Reactions contained $50 \mathrm{mM}$ HEPES pH 8.0, $5 \mathrm{mM} \mathrm{Mg}(\mathrm{OAc})_{2}, 5$ mM DTT, $100 \mu \mathrm{M}$ ATP, $5 \mu \mathrm{M}$ S679A or S679W Lon, and varying concentrations of S4 dansyl peptide or S2 non fluorescent peptide $(0-100 \mu \mathrm{M})$. The emission spectra for the dansyl peptide S4 interacting with Lon were generated by subtracting the emission spectra of the S4 dansyl peptide alone in the presence of ATP from the emission spectra of the same concentration of the S4 peptide incubated with Lon in the presence of ATP. The concomitant changes in the emission spectra of tryptophan were recorded by subtracting the emission spectra of the S4 peptide incubated with Lon and ATP from the emission spectra of the same concentration of dansylated glutamic acid incubated with Lon and ATP. 


\section{Monitoring peptide-Lon interactions}

Experiments to monitor interactions between peptide substrate with Lon were performed on a KinTek Stopped Flow controlled by the data collection software Stop Flow version $7.50 \beta$ with a $0.5 \mathrm{~cm}$ pathlength. The sample syringes were maintained at $37^{\circ} \mathrm{C}$ by a circulating water bath. Syringe A contained $5 \mu \mathrm{M}$ S679A or S679W Lon monomer with variable concentrations of S4 (10-500 $\mu \mathrm{M}), 50 \mathrm{mM}$ HEPES $\mathrm{pH} 8.0,75 \mathrm{mM}$ KOAc, $5 \mathrm{mM} \mathrm{Mg}(\mathrm{OAc})_{2}$ and $5 \mathrm{mM}$ DTT. Syringe B contained $100 \mu \mathrm{M}$ ATP, $50 \mathrm{mM}$ HEPES $\mathrm{pH}$ 8.0, $75 \mathrm{mM}$ KOAc and $5 \mathrm{mM}$ DTT. S4 binding to S679A was monitored by an increase in fluorescence (excitation $290 \mathrm{~nm}$ emission $450 \mathrm{~nm}$ long-pass filter) upon rapid mixing of the syringe contents. In addition to monitoring with excitation $290 \mathrm{~nm}$ and emission with a $450 \mathrm{~nm}$ longpass filter, experiments were performed with excitation $290 \mathrm{~nm}$ emission with a $340 \mathrm{~nm}$ band-pass filter to monitor changes in Trp fluorescence. To define the pre-steady-state period of the reaction, each time course was fit over a period of time equal to four half-lives of the pre-steady-state rate constant $\left(\mathrm{k}_{\text {lag }}\right)$ obtained from the ATP dependent peptidase reaction. The lag rate constant $\mathrm{k}_{\mathrm{lag}}$ was previously determined for each reaction condition used (23). The data shown are a result of averaging at least four traces. Each reaction condition was performed in triplicate (a total of $\geq 12$ traces obtained for each data point). The averaged time courses of S679A were fit with eq 1 describing a single exponential

$$
F=\operatorname{Aexp}^{\left(-k_{s 679}{ }^{t}\right)}+C
$$

where $\mathrm{F}$ is relative fluorescence, $\mathrm{A}$ is amplitude in relative fluorescence units, $\mathrm{t}$ is time in seconds, $\mathrm{C}$ is the endpoint, $\mathrm{k}_{\mathrm{S} 679 \mathrm{~A}}$ is the first order rate constant associated with peptide binding to S679A Lon in per seconds. It should be noted that the PMT (photomultiplier tube) sensitivity was automatically adjusted by the instrument to optimize signal to noise during acquisition of the time course data for the various concentrations of peptide used in the reactions. A higher sensitivity setting was used for the lower [S4] and a lower sensitivity setting was used for higher [S4]. As a result the relative amplitudes of the time courses do not reflect the stoichiometries of the enzyme intermediates monitored by the signals. At high concentrations of S4 (> $100 \mu \mathrm{M})$, the high absorbance of the dansyl moiety also obscures the amplitude of the fluorescence signal detected; but the first order rate constants of the reactions do not change because the dansyl absorbance in each reaction remains constant.

The time course of S679W with AMPPNP without peptide was fit with eq 2 describing a single exponential equation followed by a steady state rate

$$
\mathrm{F}=\mathrm{A}_{1} \exp ^{\left(-\mathrm{k}_{1,5679 \mathrm{~W}}{ }^{\mathrm{t}}\right)}+v_{\mathrm{ss}} \mathrm{t}+\mathrm{C}
$$

where $\mathrm{F}$ is relative fluorescence, $\mathrm{A}_{1}$ is amplitude in relative fluorescence units, $\mathrm{t}$ is time in seconds, $\mathrm{k}_{1, \mathrm{~S} 679 \mathrm{~W}}$ is the first order rate constant associated with the first phase of the reaction in per seconds, $v_{\mathrm{ss}}$ is the steady state rate in fluorescence units per second, and $\mathrm{C}$ is the endpoint. The averaged time courses of S679W with ATP and S4 peptide were fit with eq 3 describing a double exponential

$$
\mathrm{F}=\mathrm{A}_{1} \exp ^{\left(-\mathrm{k}_{1,5679 \mathrm{w}} \mathrm{t}\right)}+\mathrm{A}_{2} \exp ^{\left(-\mathrm{k}_{2,5679 \mathrm{~W}} \mathrm{t}\right)}+\mathrm{C}
$$

where $\mathrm{F}$ is relative fluorescence, $\mathrm{A}_{1}$ and $\mathrm{A}_{2}$ are amplitudes in relative fluorescence units, $\mathrm{t}$ is time in seconds, $\mathrm{C}$ is the endpoint, $\mathrm{k}_{1, \mathrm{~S} 679 \mathrm{~W}}$ is the first order rate constant associated with the first phase of the reaction in per seconds, and $\mathrm{k}_{2, \mathrm{~S} 679 \mathrm{~W}}$ is the first order rate constant associated with the second phase of the reaction in per seconds. Time courses of $\mathrm{S} 679 \mathrm{~W}$ with saturating concentrations of ATP and low concentrations of S4 dansyl peptide $(25-125 \mu \mathrm{M})$ were fit with eq 4 describing a triple exponential 


$$
F=A_{1} \exp ^{\left(-k_{1,5679 w} t\right)}+A_{2 *} \exp ^{\left(-k_{2 *, 5679 w} t\right)}+A_{2} \exp ^{\left(-k_{2,5679 w} t\right)}+C
$$

where $\mathrm{F}$ is relative fluorescence, $\mathrm{A} 1, \mathrm{~A} 2 *$ and $\mathrm{A} 2$ are amplitudes in relative fluorescence units, $\mathrm{t}$ is time in seconds, $\mathrm{C}$ is the endpoint, $\mathrm{k}_{1, \mathrm{~S} 679 \mathrm{~W}}$ is the first order rate constant associated with

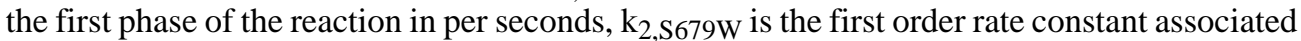
with the second phase of the reaction in per seconds and $\mathrm{k}_{2 *}, \mathrm{~S} 679 \mathrm{~W}$ is the first order rate constant for a phase in the reaction that is only visible under conditions of low peptide concentrations.

The first order rate constants were plotted as a function of substrate concentration (ATP or S4). Hyperbolic plots were fit using the data fitting program Kaleidagraph by Synergy with eq 5 describing a 2-step binding event

$$
\mathrm{k}=\mathrm{k}_{\max }[\mathrm{S}] /\left(\mathrm{K}_{\mathrm{d}}+[\mathrm{S}]\right)+k_{\mathrm{rev}}
$$

where $\mathrm{k}$ is the observed rate constant from eq 1 or eq 3 in per seconds, $\mathrm{k}_{\max }$ is the maximum forward rate constant for the second step in the binding event in per seconds, $\mathrm{k}_{\mathrm{rev}}$ is the reverse rate constant for the second step in the binding event in per seconds, $S$ is the concentration of ATP or S4 peptide, and $K_{d}$ is the equilibrium binding constant for the substrate in micromolar units. Sigmoidal plots were fit using the data fitting program Enzfitter by Biosoft with eq 6

$$
\mathrm{k}=\mathrm{k}_{\max }[\mathrm{S}]^{n} /\left(\mathrm{K}_{\mathrm{d}}+[\mathrm{S}]^{n}\right)+k_{\mathrm{rev}}
$$

where $\mathrm{k}$ is the observed rate constant from eq 1,3 or 4 in per seconds, $\mathrm{k}_{\max }$ is the maximum forward rate constant for the second step in the binding event in per seconds, $\mathrm{k}_{\mathrm{rev}}$ is the reverse rate constant for the second step in the binding event in per seconds, $S$ is the concentration of ATP or S4 peptide, $n$ is the Hill coefficient ( $n=1.6$, previously determined for Lon and our model peptide substrate (27)), the equilibrium binding constant $\mathrm{K}_{\mathrm{d}}$ is calculated from the relationship $\log \mathrm{K}_{\mathrm{d}}{ }^{\prime}=n \log \mathrm{K}_{\mathrm{d}}$.

\section{Measuring peptide binding using fluorescence anisotropy}

S4 dansyl peptide binding to the S679A Lon mutant was detected by changes in fluorescence anisotropy (excitation $340 \mathrm{~nm}$ emission $520 \mathrm{~nm}$ ) at $37^{\circ} \mathrm{C}$ on a Fluoromax-3 spectrofluorimeter (Horiba Group). Each binding reaction contained $50 \mathrm{mM} \mathrm{HEPES} \mathrm{pH} \mathrm{8.0,} 5 \mathrm{mM} \mathrm{Mg}(\mathrm{OAc})_{2}$, $5 \mathrm{mM}$ DTT, and $20 \mu \mathrm{M} \mathrm{S} 4$ dansyl peptide in the presence and absence of $1 \mathrm{mM}$ AMPPNP in a quartz microcuvette (Hellma) with a $3 \mathrm{~mm}$ path length. S679A, S679W or wild-type Lon was titrated into the cuvette $(0-192 \mu \mathrm{M})$ and the reaction was incubated at $37^{\circ} \mathrm{C}$ for 3 minutes to allow equilibrium to be reached. Higher Lon concentrations were not used due to problems with solubility of the protein. The anisotropy measurements were plotted as a function of Lon concentration and the data were fit with eq 7

$$
\mathrm{B}=\mathrm{B}_{\max }[\mathrm{S}]^{n} /\left(\mathrm{K}_{\mathrm{d}^{\prime}}+[\mathrm{S}]^{n}\right)+\mathrm{C}
$$

where $\mathrm{B}$ is the observed anisotropy, $\mathrm{B}_{\max }$ is the maximum anisotropy, $\mathrm{S}$ is the concentration of Lon added, $n$ is the Hill coefficient, $\mathrm{C}$ is the endpoint, the equilibrium binding constant $\mathrm{K}_{\mathrm{d}}$ is calculated from the relationship $\log \mathrm{K}_{\mathrm{d}}{ }^{\prime}=n \log \mathrm{K}_{\mathrm{d}}$.

\section{Results}

\section{Characterization of the E. coli Lon mutants S679A and S679W}

We generated two proteolytically inactive mutants of $E$. coli Lon to study the microscopic kinetic events occurring along the enzymatic pathway prior to peptide cleavage. Both mutants replace Ser 679, which is responsible for attacking the scissile peptide bond in a substrate, with 
either an Ala (S679A) or Trp (S679W). While both mutants display wild-type-like intrinsic and peptide-stimulated ATPase activities that are identical to wild-type Lon, both are proteolytically inactive (see supplemental information Figures A and C). As summarized in Table 1, the $\mathrm{k}_{\mathrm{cat}}$ and $\mathrm{K}_{\mathrm{m}}$ values for the ATPase activity are comparable to those obtained for wild-type Lon and suggest that the mutations do not alter ATP hydrolysis (28). In addition, we used stopped-flow spectroscopy to validate that MANT-ATP binds to both mutants identically compared to the wild type enzyme (Table 1 and supplemental information Figure B). Taken together, our data demonstrates that only the degradation of peptide is inactivated by the mutations. Furthermore, limited tryptic digestion analysis reveals that both mutants form a compact conformation resistant to digestion by trypsin upon binding to ATP (supplemental information Figure D), thereby revealing that the mutations do not affect the adenine-dependent conformational change that is found in the wild-type enzyme (27). The discovery of wild-typelike ATPase activities in both mutants is consistent with the report of Starkova et al. demonstrating that the ATPase activity can be decoupled from the proteolytic activity of Lon (19).

\section{Characterizing the binding interaction of S4 peptide with S679A by fluorescence spectroscopy}

E. coli Lon is a homo-hexamer containing three intrinsic Trp residues in each subunit. Surprisingly though, only small changes in the fluorescence of the intrinsic Trp residues of S679A are detected upon excitation at $290 \mathrm{~nm}$ in a series of reactions containing $100 \mu \mathrm{M}$ ATP and increasing concentrations of the non-fluorescent peptide S2 (YRGITCSGRQK(Bz), Figure 1A). The low signal generated from S2 binding to the Lon mutants cannot be used to monitor the kinetics of peptide interacting with the proteins. In contrast, the fluorescence of Trp residues in S679A is significantly reduced when the dansylated S4 peptide (YRGITCSGRQK(dansyl)) is used (Figure 1B and 1C). When excited at $290 \mathrm{~nm}$, the reduction in the fluorescence of Trp is accompanied by an increase in the fluorescence of the dansyl moiety in the S4 peptide (Figure 1D). An additional control was performed to correct for the decrease in trypotphan fluorescence caused by non-specific absorption of the dansyl moiety. Although a decrease in tryptophan fluorescence is observed with dansylated glutamic acid, a larger decrease in the fluorescence signal is observed with the S4 dansyl peptide (Figure 1B). The tryptophan spectra shown in Figure $1 \mathrm{C}$ were generated by subtracting the emission spectra of the $\mathrm{S} 4$ peptide incubated with Lon and ATP from the emission spectra of the same concentration of dansylated glutamic acid incubated with Lon and ATP. Collectively, Figures 1A to 1D reveal that the reduction in the fluorescence of the tryptophan residues in Lon is attributed to the specific interaction between Lon and the S4 peptide. Thus the interaction between S679A and the dansylated peptide S4 in the presence of nucleotide can be quantitatively characterized by monitoring the increase in dansyl fluorescence using stopped flow spectroscopy. Figure 2A provides the time course for the change in dansyl fluorescence generated from rapidly mixing $100 \mu \mathrm{M}$ ATP versus a preincubated solution containing $5 \mu \mathrm{M}$ S679A with $100 \mu \mathrm{M}$ S4 dansyl. The order of peptide or ATP mixing does not affect the kinetics of the reactions since identical time courses were obtained when S679A was rapidly mixed with $100 \mu \mathrm{M}$ S4 dansyl peptide (data not shown). In addition, negligible changes in the dansyl fluorescence were detected when ATP was omitted.

In addition to monitoring changes in dansyl fluorescence, these experiments could also monitor changes in Trp fluorescence (Figure 2B). The increase in dansyl fluorescence (Figure 2A) mirrors the decrease in Trp fluorescence (Figure 2B) which was detected using a $340 \mathrm{~nm}$ bandpass filter. Taken together, the increase in the dansylated peptide fluorescence time course (Figure 2A) along with the concomitant decrease in the Trp fluorescence time course (Figure 2B) suggests that peptide binding to Lon can be monitored by detecting the dansyl fluorescence time courses through excitation of the Trp residues in the Lon mutants. The increase in dansyl fluorescence most likely results from conformational changes in the enzyme in which the Trp 
residues are more accessible to interact with the dansyl moiety. However, alternative possibilities exist. For example, the signal could reflect the dansyl peptide approaching one or more of the Trp residues in Lon or a combination of both phenomena. Regardless, the detected signal is a result of the S4 dansyl peptide interacting with Lon, and is used as a reporter for monitoring the kinetics of the binding reactions.

\section{Measuring S4 dansyl peptide binding to Lon using fluorescence anisotropy}

Fluorescence anisotropy experiments were used to further characterize the equilibrium binding of S4 dansyl peptide to S679A Lon. As shown in Figure 3, S4 peptide binding to S679A Lon can be measured by titrating S679A Lon $(0-192 \mu \mathrm{M})$ into a cuvette containing $20 \mu \mathrm{M}$ of the dansylated peptide S4 and $1 \mathrm{mM}$ AMPPNP, a non-hydrolyzable analog of ATP. The binding isotherm in Figure 3 was fit to the Hill equation (eq 7) to yield a $\mathrm{K}_{\mathrm{d}}=35.2 \pm 18.6 \mu \mathrm{M}$ and a Hill coefficient (n) of $1.5 \pm 0.1$. Experiments performed using wild-type or S679A Lon in the absence of AMPPNP yielded identical binding parameters $\left(\mathrm{K}_{\mathrm{d}}=38.3 \pm 6.0 \mu \mathrm{M}, \mathrm{n}=1.5 \pm 0.1\right.$; and $\mathrm{K}_{\mathrm{d}}=49.2 \pm 28.1 \mu \mathrm{M}, \mathrm{n}=1.5 \pm 0.1$, respectively, data not shown). Comparable $\mathrm{K}_{\mathrm{d}}$ values were also obtained in the S4 peptide binding to S679W in the presence of AMPPNP (data not shown). Since neither the $\mathrm{K}_{\mathrm{d}}$ nor the Hill coefficients are affected by the presence of nucleotide, we conclude that peptide binding to Lon occurs via a rapid equilibrium process. This conclusion is supported by our previous steady-state kinetic studies revealing that Lon adopts a random ordered Bi Bi kinetic mechanism in catalyzing the ATP-dependent cleavage of a peptide bond (2).

\section{The interaction between S679A and dansyl peptide exhibits dependency toward peptide and ATP concentrations}

To evaluate the kinetics of S679A interacting with S4, we measured the stopped flow time courses of dansyl fluorescence emission ( $450 \mathrm{~nm}$ long pass filter) by exciting Trp at $290 \mathrm{~nm}$ at various S4 dansyl peptide concentrations (10 to $500 \mu \mathrm{M}$ ). The dansyl fluorescence signal measured is a result of the $\mathrm{S} 4$ dansyl peptide interacting with the Trp residues in Lon. The Trp residues are excited at $290 \mathrm{~nm}$ and the emission from the Trp residues excites the dansyl moiety on S4 either from S4 approaching a Trp residue or from a conformational change in the enzyme making the Trp residues more accessible.

The time courses were best fit to a single exponential equation (eq. 1) to yield the observed rate constants of the reactions, $\mathrm{k}_{\mathrm{S} 679 \mathrm{~A}}$. Plotting $\mathrm{k}_{\mathrm{S} 679 \mathrm{~A}}$ as a function of peptide concentration yields a sigmoidal plot shown in Figure 4A, which is indicative of a two step peptide binding mechanism (Scheme 1) (30). The assignment of a two-step binding mechanism can be explained in terms of the signal detected from S4 is generated from the S679A:dansyl peptide complex. At low peptide concentrations, the formation of enzyme:peptide contributes to the observed $\mathrm{k}_{\mathrm{S} 679 \mathrm{~A}}$ (step 1 in Scheme 1). As such, the $\mathrm{k}_{\mathrm{S} 679 \mathrm{~A}}$ values increase as the concentration of peptide increases until the enzyme is saturated with peptide. The horizontal asymptote of the plot shown in Figure 4A provides the maximum rate constant of S4 interacting with the enzyme at saturating peptide concentrations. This apparent zero-order dependency of a rateconstant towards peptide concentration is consistent with the existence of an isomerization or conformational change occurring within the enzyme:peptide complex after the initial ligand binding event (Scheme 1) which has been detected in many enzymes (30,31). Fitting the data shown in Figure 4A with eq. 6 yields the $\mathrm{K}_{\mathrm{d}}$ of $\mathrm{S} 4$ for $\mathrm{S679A}$, which is $164 \pm 35 \mu \mathrm{M}, \mathrm{n}=1.3$ \pm 0.2 (Table 2). Increasing the peptide concentration saturates the peptide binding site in S679A such that the observed rate constant becomes dominated by the forward and reverse rate constants of the second step at peptide concentrations greater than the $\mathrm{K}_{\mathrm{d}}$. Under these conditions, the forward and reverse rate constants reach a maximum, which is $0.74 \pm 0.10$ $\mathrm{s}^{-1}$ and $0.19 \pm 0.01 \mathrm{~s}^{-1}$, respectively (Table 2 ). 
The interaction between $5 \mu \mathrm{M}$ of S679A and $500 \mu \mathrm{M}$ S4 dansyl peptide $\left(\sim 3 \times \mathrm{K}_{\mathrm{d}}\right.$ of S679A, see Table 2) is also dependent on the concentration of ATP as illustrated in Figure 4B. The time courses (excitation $290 \mathrm{~nm}$, emission $450 \mathrm{~nm}$ ) were best fit to a single exponential curve (eq. 1) to yield the rate constants, $\mathrm{k}_{\mathrm{S} 679 \mathrm{~A}}$, for the reactions in which the concentration of ATP is varied. Plotting the observed rate constants at the corresponding concentration of ATP $(0.5$ $\mu \mathrm{M}$ to $50 \mu \mathrm{M}$ ) yields a hyperbolic plot, which upon fitting with eq 5 , yields a $\mathrm{K}_{\mathrm{d}}$ of $7.4 \pm 2.5$ $\mu \mathrm{M}$ for ATP, a forward rate constant $\left(\mathrm{k}_{\mathrm{S} 679 \mathrm{~A}, \max }\right)$ of $0.54 \pm 0.04 \mathrm{~s}^{-1}$ and a reverse rate constant $\left(\mathrm{k}_{\text {rev }, \mathrm{S} 679 \mathrm{~A}}\right)$ of $0.19 \pm 0.03 \mathrm{~s}^{-1}$ (Figure 4B, Table 2).

\section{The S679W mutant shows an ATP-dependent conformational change in Trp that is independent of peptide}

The S679W mutant was generated to probe the existence of an allosteric communication between the ATPase site and the protease site in Lon. As Trp fluorescence is sensitive to changes in its local environment, the replacement of the $679 \mathrm{~S}$ with a Trp residue allows the detection of a conformational change in the proteolytic site in Lon resulting from ATP or AMPPNP binding (32). Figure 5 provides representative stopped flow time courses monitoring the changes in Trp fluorescence of S679W in the absence and presence of ATP as well as in the presence of AMPPNP or ADP without the presence of peptide. A decrease in the Trp fluorescence is detected only in the presence of ATP or AMPPNP but not ADP, suggesting that the gamma phosphate moiety present in ATP and AMPPNP is needed to induce the changes in Trp fluorescence. The time course which contains ATP is best fit with the single exponential

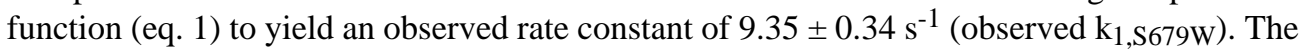
time course which contains the non-hydrolyzable analog AMPPNP, is best fit with the single exponential function followed by a steady-state rate shown in eq 2 to yield an observed rate constant of $0.94 \pm 0.02 \mathrm{~s}^{-1}$ and a steady-state rate of 0.02 fluorescence units per second to account for the decrease in the Trp fluorescence. As the observed rate constant for the change in Trp fluorescence is 10-fold faster in the presence of ATP than AMPPNP, it is likely that the formation of this enzyme form is facilitated by the hydrolysis of ATP. Furthermore, the presence of peptide substrate is not needed for this conformational change.

\section{Compared to ATP, AMPPNP supports the peptide-Lon interaction at a reduced rate}

An increase in dansyl fluorescence was detected when $5 \mu \mathrm{M}$ of S679W pre-incubated with 100 $\mu \mathrm{M}$ S4 was mixed with $100 \mu \mathrm{M}$ ATP (Figure 6A). The samples were excited at $290 \mathrm{~nm}$ and the fluorescence signals were detected using a $450 \mathrm{~nm}$ longpass filter, which monitored the fluorescence signal generated from the S4 dansyl peptide. We have previously shown that AMPPNP supports peptide hydrolysis by Lon with a $\mathrm{k}_{\text {cat }}$ that is $\sim 7$ fold lower and a lag phase that is $\sim 10$-fold longer than those detected for ATP $(1,2)$. To explore how AMPPNP effects the peptide-Lon interaction we used $5 \mu \mathrm{M}$ S679W with $500 \mu \mathrm{M}$ S4 dansyl peptide and rapidly mixed it with $100 \mu \mathrm{M}$ AMPPNP. The resulting time course is shown in Figure 6B. The time course was fit to a double exponential equation (eq 3 ) and the resulting rate constants,

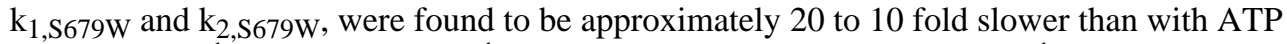
$\left(0.50 \pm 0.01 \mathrm{~s}^{-1}\right.$ and $0.04 \pm 0.01 \mathrm{~s}^{-1}$, respectively) compared to $7.6 \pm 1.0 \mathrm{~s}^{-1}$ and $0.57 \pm 0.10$ $\mathrm{s}^{-1}$ in the presence of ATP under identical reaction conditions (see Table 2). The same experiment was also performed in the presence of ADP instead of AMPPNP. As shown in Figure $6 \mathrm{~B}$, no change in fluorescence is detected in the reaction containing ADP, indicating that the gamma-phosphate position of ATP is needed for generating the conformational changes detected in this study.

\section{Fluorescent analysis of the interaction of S679W and the dansylated peptide}

The interaction between S679W and the S4 peptide was examined using stopped flow techniques described above for characterizing the S679A mutant. Figure 7A shows selected 
time courses reflecting the changes in the dansyl fluorescence of S4 following excitation of the Trp residues in S679W at varying concentrations of ATP $(0.5-50 \mu \mathrm{M})$. According to Figure 7A, the time courses obtained at concentrations of ATP at $<5 \mu \mathrm{M}$ and at $500 \mu \mathrm{M}$ S4 $\left(\sim 3 \times \mathrm{K}_{\mathrm{d}}\right.$ of S4) display an increase followed by a slower decrease in dansyl fluorescence. At $\geq 5 \mu \mathrm{M}$ ATP however, the time courses only show an increase in dansyl fluorescence.

Concurrent decrease in the Trp fluorescence time courses which mirror the observed dansyl fluorescence data were also detected (see supplemental information Figure E). In an earlier study, we demonstrated that the ATPase activity of Lon was negligible at $<5 \mu \mathrm{M}$ ATP, and the enzyme was only $50 \%$ saturated with ATP at $10 \mu \mathrm{M}$ of the nucleotide $(23,28,33)$. Therefore the time courses detected at $\geq 5 \mu \mathrm{M}$ ATP likely reflect the conformational states of S679W accompanied by ATP hydrolysis. Comparing the data obtained at $<5 \mu \mathrm{M}$ versus at $\geq 5 \mu \mathrm{M}$ ATP reveals that the direction of the fluorescence changes in the second phase is reversed as the concentration of ATP increases. As the proteolytic residue $679 \mathrm{~S}$ is replaced with a Trp, the observed changes in the direction of the fluorescence time courses at increasing concentrations of ATP could be attributed to the conformation of the proteolytic site of Lon varying with the occupancy of nucleotide and/or the ATPase activity of the enzyme. As such, optimal peptide cleavage by Lon requires the hydrolysis of ATP to fully activate the proteolytic site.

Identical experiments were performed varying the concentration of $\mathrm{S} 4(25-500 \mu \mathrm{M})$ using a fixed concentration of $100 \mu \mathrm{M}$ ATP $\left(10 \times \mathrm{K}_{\mathrm{d}}\right.$ of the ATPase site (33)). Figure 7B shows selected time courses reflecting the changes in the dansyl fluorescence of S4 upon incubating with S679W at a saturating level of ATP. The time courses obtained at sub $\mathrm{K}_{\mathrm{d}}$ levels of S4 (see Table 2 for $K_{d}$ of $S 4$ peptide) are triphasic in which there is an initial increase followed by a transient decrease culminating in a final phase showing an increase in fluorescence signal (time courses a and b). At the low peptide concentrations $(25-100 \mu \mathrm{M})$, the time courses fit best to

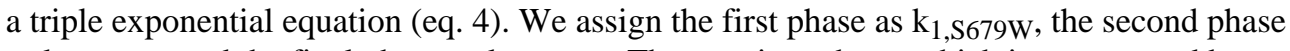

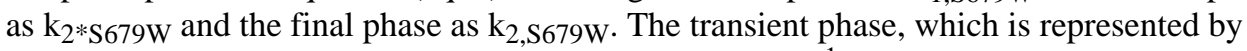
$\mathrm{k}_{2} * \mathrm{~S} 679 \mathrm{~W}$, is independent of [S4] $\left(\mathrm{k}_{2} * \mathrm{~S} 679 \mathrm{~W}=0.95 \pm 0.30 \mathrm{~s}^{-1}\right)$. As the concentration of peptide is increased, the time courses become biphasic as the intermediate phase diminishes in intensity, and the data were fit best to the double exponential function (eq. 3). We propose that the second transient phase "disappears" at higher S4 concentrations since the rate constant

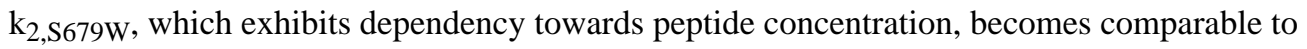
the values of $\mathrm{k}_{2} * \mathrm{~S} 697 \mathrm{~W}$. As a result, only two apparent rate constants that are represented by $\mathrm{k}_{1, \mathrm{~S} 679 \mathrm{~W}}$ and $\mathrm{k}_{2, \mathrm{~S} 679 \mathrm{~W}}$ are detected when the concentration of $\mathrm{S} 4$ is higher than the $\mathrm{K}_{\mathrm{d}}$ of peptide. The mechanistic feature that is responsible for generating the transient phase is not clear. However, these reactions were conducted at $100 \mu \mathrm{M}$ ATP, where Lon catalyzes the hydrolysis of ATP with a pre-steady-state burst rate of $\sim 10 \mathrm{~s}^{-1}$ and a steady-state turnover rate constant of $\sim 0.8 \mathrm{~s}^{-1}(23)$. Therefore it is possible that the transient phase detected at low concentrations of S4 is attributed to the exchange of ADP generated from the first turnover of nucleotide hydrolysis with the exchange of ATP in the enzyme to maintain protein interaction with S4. Additional experimentation will be required to resolve this issue.

Collectively the biphasic time course data obtained at $500 \mu \mathrm{M} \mathrm{S} 4$ and varying [ATP] or at varying [S4] and saturating ATP were best fit with the double exponential function defined by

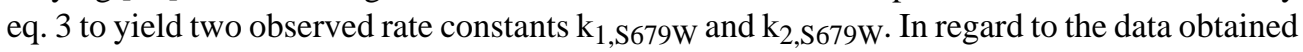

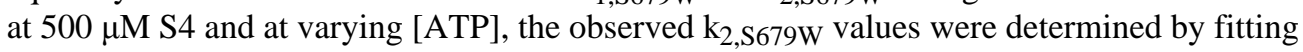

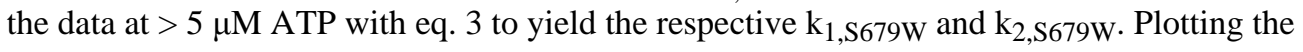

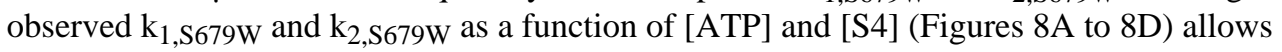
the extrapolation of the maximal rate constants for the respective phase of the reactions. Figures $8 \mathrm{~A}$ and $8 \mathrm{~B}$ collectively show that $\mathrm{k}_{1, \mathrm{~S} 679 \mathrm{~W}}$ exhibits dependency towards [ATP] but not

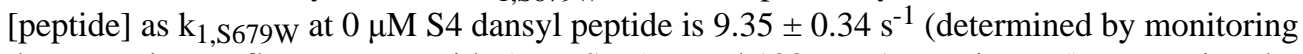
decreases in Trp fluorescence with $5 \mu \mathrm{M}$ S679W and $100 \mu \mathrm{M}$ ATP, Figure 5). Increasing the

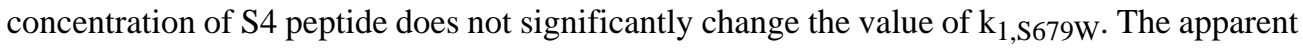


increase in the $\mathrm{k}_{1, \mathrm{~S} 679 \mathrm{~W}}$ values discerned in Figure 8A may be due to uncertainty involved in

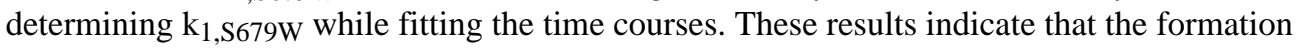

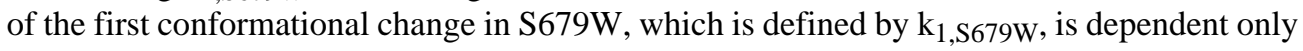

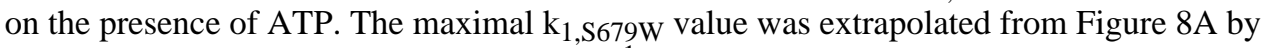

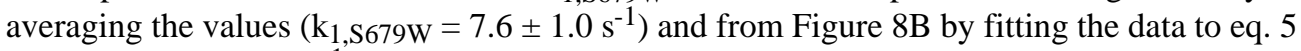
$\left(\mathrm{k}_{1, \mathrm{~S} 679 \mathrm{~W}}=5.3 \pm 0.6 \mathrm{~s}^{-1}\right)$. All kinetic parameters are reported in Table 2 .

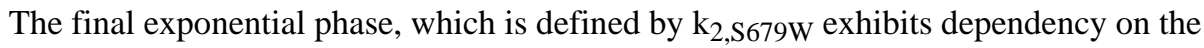
concentration of ATP and peptide. Figures $8 \mathrm{C}$ and $8 \mathrm{D}$ show the plots relating the observed rate constants to the indicated ATP or peptide concentrations. The $\mathrm{K}_{\mathrm{d}}$ values for ATP and peptide, as well as the maximal rate constant $\left(\mathrm{k}_{2, \mathrm{~S} 679 \mathrm{~W} \text {,max }}\right)$ for each fit is summarized in Table 2 . We report the $\mathrm{k}_{\text {rev }}$ rate constant for varying concentrations of ATP as "not determined" in Table 2 as the standard error for this number was rather high $\left(0.08 \pm 0.5 \mathrm{~s}^{-1}\right)$. The $\mathrm{k}_{\mathrm{rev}}$ rate constant is the y-intercept in the plot and visually it is approaching zero. Despite the uncertainty involved, the data reveals that the reverse rate constant is slow and nearly negligible in comparison to the forward rate constants.

\section{Discussion}

Lon is a serine protease whose activity is regulated by the binding and hydrolysis of ATP. In this study we demonstrated that the microscopic events associated with peptide interacting with Lon prior to its cleavage can be monitored by the fluorescence signal generated between dansylated peptide substrate (S4) and tryptophan residues in Lon. We employed pre-steadystate kinetic techniques to monitor the dynamics of a dansylated peptide (designated S4) interacting with two proteolytically inactive E. coli Lon mutants, S679A and S679W. Both mutants contain three Trp residues that are intrinsic to the wild-type enzyme: $297 \mathrm{~W}$ and 303W located at the proximity of the ATPase domain (based on the primary amino acid sequence (15)) and $603 \mathrm{~W}$ at the vicinity of the active site Ser (based on the truncated crystal structure of the protease domain (16)). The S679W mutant contains an additional Trp residue that replaces the proteolytic active site Ser at position 679. Upon binding to the target protein, the fluorescence signal associated with a dansylated peptide is indirectly enhanced by excitation of the intrinsic Trp residues located within the protease. Therefore we can determine the kinetic mechanism of peptide interacting with S679A and S679W by analyzing the fluorescence time courses obtained in this study.

The detection of a $\mathrm{k}_{\mathrm{S} 679 \mathrm{~A}}$ sharing a comparable value as $\mathrm{k}_{2, \mathrm{~S} 679 \mathrm{~W}}$ as well as dependency towards [ATP] and [S4] suggests that the same kinetic step is being examined in the respective mutants. A two-step S4 binding mechanism is proposed. The first step involves the formation of a Lon:ATP:S4 complex, and the second step is a conformational change in the complex, occurring after ATP is hydrolyzed. The kinetic progression of the second step is detected by the increase in dansyl fluorescence in the S4 peptide upon excitation of the Trp residues in the Lon mutants. At low [peptide], the binding of S4 to Lon in the presence of ATP limits the observed rate constant. Increasing the concentration of peptide leads to enzyme saturation such that the observed rate constants reach a finite value, which is defined by the asymptote of the plots shown in Figures 4A and 8C. Previously we reported the degradation of a fluorogenic derivative of the $\mathrm{S} 4$ peptide exhibiting sigmodial kinetics, yielding a Hill coefficient of 1.6 (27). The detection of a comparable Hill coefficient in the data shown in Figures 3, 4A and 8C is consistent with our previous finding. Likewise, the hyperbolic plots shown in Figures 4B and $8 \mathrm{~B}$ reveal that the fluorescence signal detected in this study reflects a conformational change in the enzyme after the initial formation of a Lon:ATP:S4 complex.

Although both S679A and S679W show the same kinetic behavior toward the binding and hydrolysis of ATP, as well as their interactions with S4, S679W displays an additional 
fluorescent signal that is dependent on the concentration of nucleotide but not peptide.

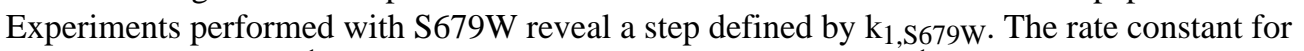
this step is $7.6 \pm 1.0 \mathrm{~s}^{-1}$ in the presence of ATP and is $0.50 \pm 0.01 \mathrm{~s}^{-1}$, which is $\sim 10$-fold lower,

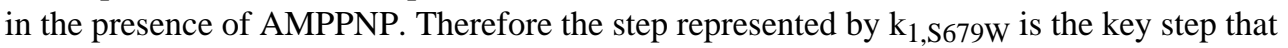
distinguishes the ATP versus AMPPNP bound enzyme form in Lon. Previously we demonstrated that fluorescently labeled ATP and AMPPNP bind to $E$. coli Lon with an identical kinetic mechanism but peptide bond cleavage is 7 to 10-fold faster in the presence of ATP

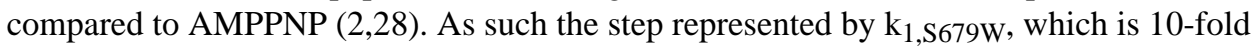
higher in the presence of ATP than AMPPNP, contributes to the observed difference in the ATP-versus AMPPNP-dependent peptidase activity of Lon and must occur after nucleotide binding but before the step representing $\mathrm{k}_{2, \mathrm{~S} 679 \mathrm{~W}}\left(\mathrm{k}_{2, \mathrm{~S} 679 \mathrm{~W}}=0.57 \pm 0.10 \mathrm{~s}^{-1}\right.$, Table 2$)$.

The ATP-dependent step is detected only in the S679W but not the S679A mutant. Therefore, we propose this step monitors the changes in the local environment surrounding residue 679 in Lon. In the wild type enzyme, such a change, which is induced by the binding and hydrolysis of ATP, may be needed to activate the proteolytic residue 679S. This proposal is made on the basis of a previous observation made in our lab showing that inhibition of the protease activity of Lon by the peptide boronate MG262 requires the presence of ATP. As the boronate moiety in MG262 functions to sequester the nucleophilic side chain of 679S $(34,35)$, the observed dependency toward ATP in protease inhibition provides support for an allosteric activation of the active site in Lon.

Through previous kinetic analyses, we have constructed a kinetic model to account for the first turnover of the ATP-dependent peptide bond cleavage activity of $E$. coli Lon. The data presented in this study is consistent with the proposed mechanism that is summarized in Figure 9. Free enzyme is represented by form I. For simplicity, the enzyme is shown as a dimer with the ATPase and SSD domain in green and the protease domain in blue. The active site serine is shown in red. First, ATP and peptide bind to the enzyme in a random mechanism (step 1, form II), followed by a conformational change that is induced by nucleotide binding (step 2, form III). Previously, our lab utilized MANT-ATP and MANT-AMPPNP to study the binding of ATP to Lon (28). This study showed that ATP and AMPPNP bind to Lon in an identical manner wherein ATP or AMPPNP binds to Lon with a rate constant of $0.7 \mu \mathrm{M}^{-1} \mathrm{~s}^{-1}$ (step 1, Figure 9) followed by a nucleotide binding induced conformational change $\left(k_{N T P}=5 \mathrm{~s}^{-1}\right.$, step 2, Figure 9). Equilibrium peptide binding experiments performed in this study indicate that peptide initially binds to Lon independent of nucleotide (Figure 3,Scheme 1, step 1). This result corroborates our previous steady-state product inhibition studies which indicated peptide and ATP likely bind to Lon in a random order to form the Lon:ATP:peptide complex (2). As the formation of enzyme form IV (step 3) can only be measured with the S679W Lon mutant and it is only dependent on nucleotide (completely independent of peptide) we propose this step involves an allosteric activation of the catalytic serine residue within the protease domain wherein the active site undergoes a gross conformational change.

We propose herein that the slow phase leading up to peptide hydrolysis and responsible for the lag kinetics is the formation of enzyme form V (step 4, Figure 1) $(2,23)$. We are able to measure this step using both the S679A and S679W Lon mutants. Work by Ishikawa et al. on a related ATP dependent protease, ClpAP, showed that substrates are translocated from an initial binding site into the proteolytic chamber (22). ClpAP and Lon are both members of the AAA+ (ATPases associated with a variety of cellular activities) family of proteases and as a slow peptide translocation step has been shown in ClpAP, we propose the slow step we observe prior to peptide hydrolysis in Lon $\left(\mathrm{k}_{2, \mathrm{~S} 679 \mathrm{~W}}\right.$ and $\mathrm{k}_{\mathrm{S} 679 \mathrm{~A}}$; form V, Figure 1$)$ is also a peptide translocation event. As such, the slow phase could be a peptide delivery event whereby the peptide moves from the initial peptide binding site at the top of the self-compartmentalized structure near the ATPase domain, down to the protease domain where it is degraded. In form 
VI (step 5) peptide is hydrolyzed followed by product release. The idea of the dansylated peptide "moving" towards the proteolytic site in Lon has been proposed based upon the discovery of a peptide translocation event occurring in ATP-dependent proteases that are related to Lon (20-22). Recently, Reid and co-workers labeled the protease active site of ClpAP, a heterosubunit ATP-dependent protease belonging to the same family as Lon, with EDANS (5-(2-(acetamido)ethylamino)naphthalene-1-sulfonic acid) and polypeptide substrates with fluorescein. They used FRET between the two fluorophores to demonstrate translocation of the substrate into the proteolytic active site (21). Unlike the ClpAP experiments, our system has multiple Trp residues that may interact with the dansyl moiety in S4. Therefore, our work cannot conclusively evaluate whether the signal is solely attributed to peptide translocation. However, because the signal is detected only when Trp and dansyl are nearby one another, it is possible that the signal could be reflecting peptide translocation, which may be accompanied by a conformational change(s) within the enzyme. To further test our kinetic model, we utilized the program KinFitSim (29) to simulate the pre-steady-state lag phase of the peptidase reaction as well as the interaction of S679W and the dansylated peptide. A close correlation was found between the experimental and simulated data providing further support for our proposed mechanism. The detailed simulation data is provided in the supporting information.

In conclusion, we have utilized stopped flow fluorescence spectroscopy to evaluate the steps leading up to peptide hydrolysis in Lon. We have provided evidence for two distinct conformational change steps along the pathway. One of these steps (step 4, form V, Figure 9) is relatively slow and we propose it is a peptide translocation/delivery event. Another step (step 3 , form IV, Figure 9) is particularly valuable in understanding the catalytic advantage offered by ATP over AMPPNP as this is the first time differences between ATP and AMPPNP have been assigned to a specific step. Additional experimentation is currently underway using the techniques described here and other nucleotides to further study the role of ATP binding and hydrolysis in activating Lon activity. Furthermore, the mechanism described herein is a valuable tool and will be used as a template in elucidating the mechanism of how Lon processes multiple sites in a full length protein such as lambda $\mathrm{N}$.

\section{Supplementary Material}

Refer to Web version on PubMed Central for supplementary material.

\section{Acknowledgements}

We would like to thank Gordon Hammes, Anthony Berdis, Diana Barko, Greg Tochtrop and Mary Barkley for helpful discussions and suggestions during the preparation of this manuscript.

This work was supported by the NIH Grant GM067172

\section{References}

1. Lee I, Berdis AJ. Adenosine triphosphate-dependent degradation of a fluorescent lambda N substrate mimic by Lon protease. Anal Biochem 2001;291:74-83. [PubMed: 11262158]

2. Thomas-Wohlever J, Lee I. Kinetic characterization of the peptidase activity of Escherichia coli Lon reveals the mechanistic similarities in ATP-dependent hydrolysis of peptide and protein substrates. Biochemistry 2002;41:9418-9425. [PubMed: 12135363]

3. Charette MF, Henderson GW, Markovitz A. ATP hydrolysis-dependent protease activity of the lon (capR) protein of Escherichia coli K-12. Proc Natl Acad Sci U S A 1981;78:4728-4732. [PubMed: 6458036]

4. Chung $\mathrm{CH}$, Goldberg AL. The product of the lon (capR) gene in Escherichia coli is the ATP-dependent protease, protease La. Proc Natl Acad Sci U S A 1981;78:4931-4935. [PubMed: 6458037] 
5. Goff SA, Goldberg AL. Production of abnormal proteins in E. coli stimulates transcription of lon and other heat shock genes. Cell 1985;41:587-595. [PubMed: 3886165]

6. Goldberg AL, Moerschell RP, Chung CH, Maurizi MR. ATP-dependent protease La (lon) from Escherichia coli. Methods Enzymol 1994;244:350-375. [PubMed: 7845219]

7. Goldberg AL, Waxman L. The role of ATP hydrolysis in the breakdown of proteins and peptides by protease La from Escherichia coli. J Biol Chem 1985;260:12029-12034. [PubMed: 2931432]

8. Gottesman S, Gottesman M, Shaw JE, Pearson ML. Protein degradation in E. coli: the Ion mutation and bacteriophage lambda $\mathrm{N}$ and cll protein stability. Cell 1981;24:225-233. [PubMed: 6453650]

9. Maurizi MR. Proteases and protein degradation in Escherichia coli. Experientia 1992;48:178-201. [PubMed: 1740190]

10. Takaya A, Suzuki M, Matsui H, Tomoyasu T, Sashinami H, Nakane A, Yamamoto T. Lon, a stressinduced ATP-dependent protease, is critically important for systemic Salmonella enterica serovar typhimurium infection of mice. Infect Immun 2003;71:690-696. [PubMed: 12540547]

11. Takaya A, Tomoyasu T, Tokumitsu A, Morioka M, Yamamoto T. The ATP-dependent lon protease of Salmonella enterica serovar Typhimurium regulates invasion and expression of genes carried on Salmonella pathogenicity island 1. J Bacteriol 2002;184:224-232. [PubMed: 11741864]

12. Robertson GT, Kovach ME, Allen CA, Ficht TA, Roop RM 2nd. The Brucella abortus Lon functions as a generalized stress response protease and is required for wild-type virulence in BALB/c mice. Mol Microbiol 2000;35:577-588. [PubMed: 10672180]

13. Bota DA, Ngo JK, Davies KJ. Downregulation of the human Lon protease impairs mitochondrial structure and function and causes cell death. Free Radic Biol Med 2005;38:665-677. [PubMed: 15683722]

14. Amerik A, Chistiakov LG, Ostroumova NI, Gurevich AI, Antonov VK. Cloning, expression and structure of the functionally active shortened lon gene in Escherichia coli. Bioorg Khim 1988;14:408411. [PubMed: 3289547]

15. Chin DT, Goff SA, Webster T, Smith T, Goldberg AL. Sequence of the lon gene in Escherichia coli. A heat-shock gene which encodes the ATP-dependent protease La. J Biol Chem 1988;263:1171811728. [PubMed: 3042779]

16. Botos I, Melnikov EE, Cherry S, Tropea JE, Khalatova AG, Rasulova F, Dauter Z, Maurizi MR, Rotanova TV, Wlodawer A, Gustchina A. The catalytic domain of Escherichia coli Lon protease has a unique fold and a Ser-Lys dyad in the active site. J Biol Chem 2004;279:8140-8148. [PubMed: 14665623]

17. Park SC, Jia B, Yang JK, Van DL, Shao YG, Han SW, Jeon YJ, Chung CH, Cheong GW. Oligomeric structure of the ATP-dependent protease La (Lon) of Escherichia coli. Mol Cells 2006;21:129-134. [PubMed: 16511355]

18. Maurizi MR. Degradation in vitro of bacteriophage lambda N protein by Lon protease from Escherichia coli. J Biol Chem 1987;262:2696-2703. [PubMed: 2950089]

19. Starkova NN, Koroleva EP, Rumsh LD, Ginodman LM, Rotanova TV. Mutations in the proteolytic domain of Escherichia coli protease Lon impair the ATPase activity of the enzyme. FEBS Lett 1998;422:218-220. [PubMed: 9490010]

20. Lee C, Schwartz MP, Prakash S, Iwakura M, Matouschek A. ATP-dependent proteases degrade their substrates by processively unraveling them from the degradation signal. Mol Cell 2001;7:627-637. [PubMed: 11463387]

21. Reid BG, Fenton WA, Horwich AL, Weber-Ban EU. ClpA mediates directional translocation of substrate proteins into the ClpP protease. Proc Natl Acad Sci U S A 2001;98:3768-3772. [PubMed: 11259663]

22. Ishikawa T, Beuron F, Kessel M, Wickner S, Maurizi MR, Steven AC. Translocation pathway of protein substrates in ClpAP protease. Proc Natl Acad Sci U S A 2001;98:4328-4333. [PubMed: 11287666]

23. Vineyard D, Patterson-Ward J, Berdis AJ, Lee I. Monitoring the Timing of ATP Hydrolysis with Activation of Peptide Cleavage in Escherichia coli Lon by Transient Kinetics. Biochemistry 2005;44:1671-1682. [PubMed: 15683251]

24. Epps D, Schostarez H, Argoudelis CV, Poorman R, Hinzmann J, Sawyer TK, Mandel F. An Experimental Method for the Determination of Enzyme-Competitive Inhibitor Dissociation 
Constants from Displacement Curves: Application to Human Renin Using Fluorescence Energy Transfer to a Synthetic Dansylated Inhibitor Peptide. Analytical Biochemistry 1989;181:172-181. [PubMed: 2683862]

25. Fattori D, Urbani A, Brunetti M, Ingenito R, Pessi A, Prendergast K, Narjes F, Matassa VG, De Francesco R, Steinkuhler C. Probing the active site of the hepatitis C virus serine protease by fluorescence resonance energy transfer. J Biol Chem 2000;275:15106-15113. [PubMed: 10809747]

26. Gilbert SP, Mackey AT. Kinetics: a tool to study molecular motors. Methods 2000;22:337-354. [PubMed: 11133240]

27. Patterson J, Vineyard D, Thomas-Wohlever J, Behshad R, Burke M, Lee I. Correlation of an adeninespecific conformational change with the ATP-dependent peptidase activity of Escherichia coli Lon. Biochemistry 2004;43:7432-7442. [PubMed: 15182186]

28. Vineyard D, Zhang X, Lee I. Transient kinetic experiments demonstrate the existence of a unique catalytic enzyme form in the peptide-stimulated ATPase mechanism of Escherichia coli Lon protease. Biochemistry 2006;45:11432-11443. [PubMed: 16981703]

29. Svir IB, Klymenko OV, Platz MS. 'KINFITSIM'--a software to fit kinetic data to a user selected mechanism. Comput Chem 2002;26:379-386. [PubMed: 12139421]

30. Johnson, KA. Practical Approach Series. Oxford University Press; 2003.

31. Cook, P.; Cleland, WW. Enzyme Kinetics and Mechanism. Garland Science; New York: 2007.

32. Lakowicz, JR. Principles of Fluorescence Spectroscopy. second. Plenum; New York: 1999.

33. Vineyard D, Patterson-Ward J, Lee I. Single-Turnover Kinetic Experiments Confirm the Existence of High- and Low-Affinity ATPase Sites in Escherichia coli Lon Protease. Biochemistry 2006;45:4602-4610. [PubMed: 16584195]

34. Frase H, Lee I. Peptidyl boronates inhibit Salmonella enterica serovar Typhimurium Lon protease by a competitive ATP-dependent mechanism. Biochemistry 2007;46:6647-6657. [PubMed: 17497890]

35. Frase H, Hudak J, Lee I. Identification of the proteasome inhibitor MG262 as a potent ATP-dependent inhibitor of the Salmonella enterica serovar Typhimurium Lon protease. Biochemistry 2006;45:8264-8274. [PubMed: 16819825]

36. Menon AS, Goldberg AL. Binding of nucleotides to the ATP-dependent protease La from Escherichia coli. J Biol Chem 1987;262:14921-14928. [PubMed: 3312196]

\section{The abbreviations used are}

ATP

adenosine triphosphate

ADP

adenosine diphosphate

AMPPNP

adenylyl 5-imidodiphosphate

DTT

dithiothreitol

Abz

anthranilamide

Bz

benzoic acid

MANT

$2^{\prime}$-(or 3') $O$-(N-methylanthraniloyl)

HEPES

$\mathrm{N}$-2-Hydroxyethylpiperazine-N'ethanesulphonic acid 
$\mathbf{K} \mathbf{P}_{\mathbf{i}}$

potassium phosphate

$\operatorname{Mg}(\mathrm{OAc})_{2}$

magnesium acetate

KOAc

potassium acetate

PEI-cellulose

polyethyleneimine-cellulose

dlu

density light unit

TPCK

N-p-tosyl-L-phenylalanine chloromethyl ketone

SBTI

soybean trypsin inhibitor

$\lambda \mathbf{N}$

also known as the lambda $\mathrm{N}$ protein, a lambda phage protein that allows $E$. coli RNA polymerase to transcribe through termination signals in the early operons of the phage

FRET

fluorescence resonance energy transfer

S1

a fluorescent peptide substrate of Lon developed by our lab based on the $\lambda \mathrm{N}$ protein $\left(3-\mathrm{NO}_{2}\right)$ YRGITCSGRQK(Abz), (1))

S2

a non-fluorescent analog of S1 (YRGITCSGRQK(Bz),(2))

S3

$(10 \% \mathrm{~S} 1+90 \% \mathrm{~S} 2$; this substrate mixture was used to correct for the inner filter effect otherwise observed at high peptide substrate concentration;(2))

S4

is a peptide with the same sequence as S2 with a dansyl fluorophore (YRGITCSGRQK(dansyl)) and was used in this study. 


\section{Figure 1A}

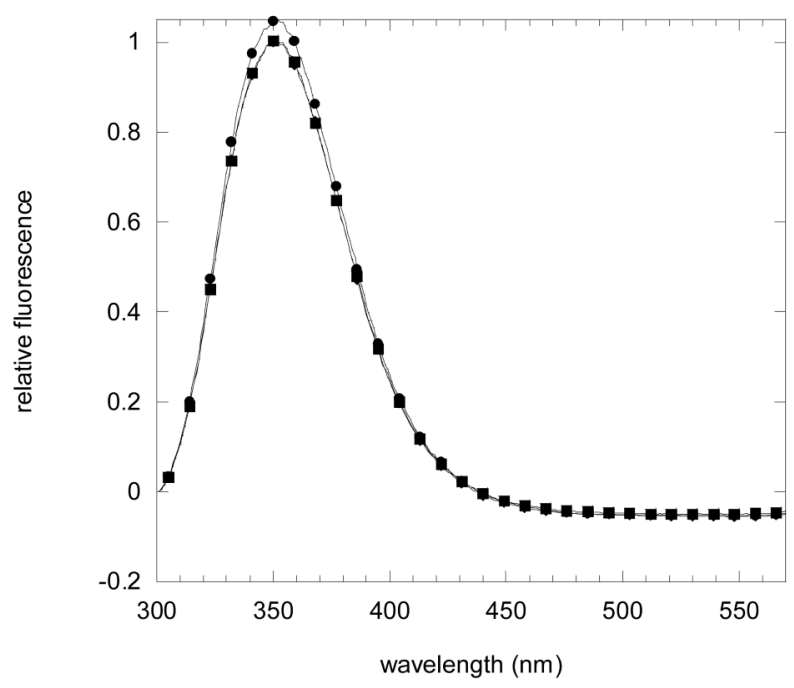

Figure 1B

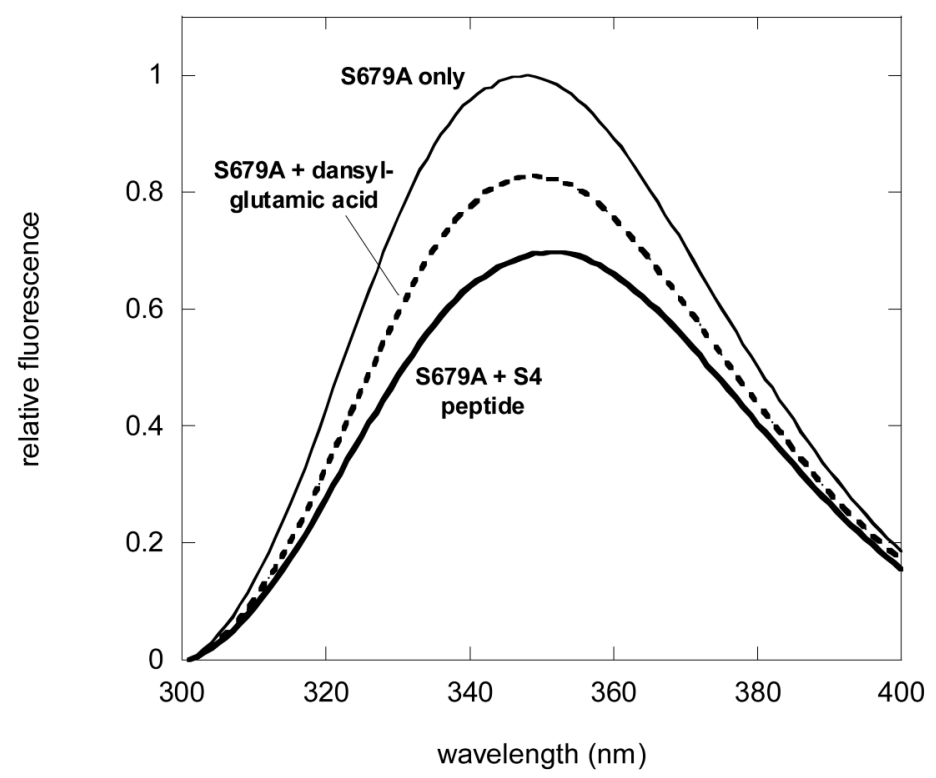

Biochemistry. Author manuscript; available in PMC 2008 November 27. 
Figure 1C

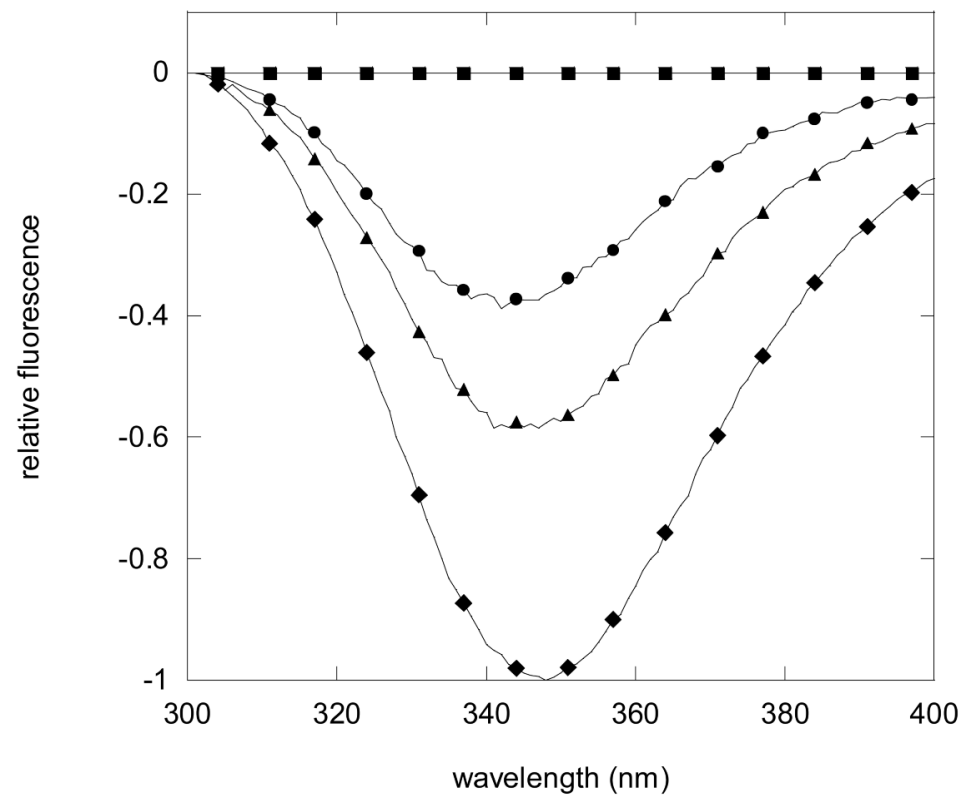

Figure 1D

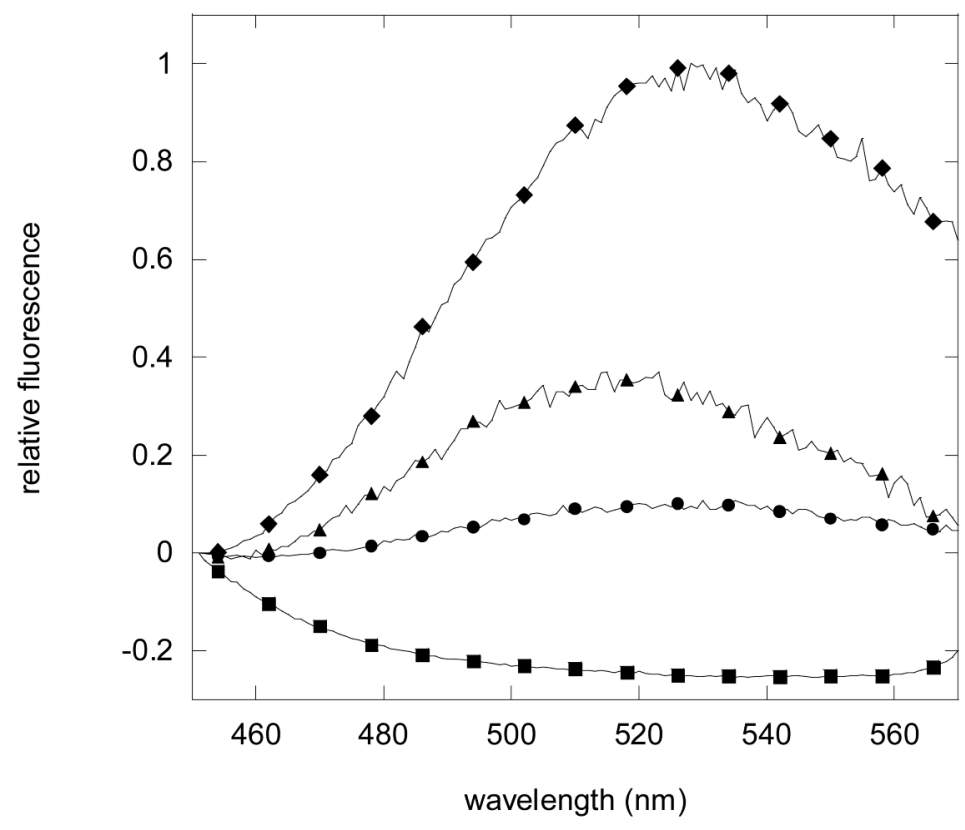

Figure 1.

(A) Fluorescent emission scans of S679A with non-fluorescent S2 peptide. Five micromolar S679A was incubated with $100 \mu \mathrm{M}$ ATP and $(\bullet) 0 \mu \mathrm{M},(\bullet) 25 \mu \mathrm{M},(\diamond) 100 \mu \mathrm{M}$ of the nonfluorescent $\mathrm{S} 2$ peptide. The sample was excited at $290 \mathrm{~nm}$ and emission was monitored from $300 \mathrm{~nm}$ to $570 \mathrm{~nm}$. No changes in tryptophan fluorescence are detected. Similar results were obtained with the S679W Lon mutant.

(B) Fluorescent emission scan of S679A with S4 dansylated peptide and dansylated glutamic acid. Five micromolar S679A was incubated with $100 \mu \mathrm{M}$ ATP and $50 \mu \mathrm{M}$ of the S4 dansylated peptide or $50 \mu \mathrm{M}$ of dansylated glutamic acid. The sample was excited at $290 \mathrm{~nm}$ and emission was monitored from $300 \mathrm{~nm}$ to $400 \mathrm{~nm}$. A decrease in tryptophan fluorescence at $350 \mathrm{~nm}$ is 
observed with dansylated glutamic acid, however there is a greater decrease with the $\mathrm{S} 4$ dansyl peptide. Similar results were obtained with the S679W Lon mutant.

(C). Corrected S679A tryptophan emission spectra. Five micromolar S679A and $100 \mu \mathrm{M}$ ATP was incubated with (•) $0 \mu \mathrm{M},(\bullet) 25 \mu \mathrm{M},(\boldsymbol{\Delta}) 50 \mu \mathrm{M},(\diamond) 100 \mu \mathrm{M}$ S4 dansyl peptide or dansylated glutamic acid. The samples were excited at $290 \mathrm{~nm}$ and emission was detected from $300 \mathrm{~nm}$ to $400 \mathrm{~nm}$. The spectra shown were corrected by subtracting the emission spectra of S4 dansyl peptide with Lon and ATP from a control reaction containing dansylated glutamic acid, Lon and ATP.

(D). Corrected emission spectra for the dansyl moiety on the S4 peptide. Five micromolar S679A was incubated with $100 \mu \mathrm{M}$ ATP and (•) $0 \mu \mathrm{M},(\bullet) 25 \mu \mathrm{M},(\boldsymbol{\Delta}) 50 \mu \mathrm{M},(\diamond) 100 \mu \mathrm{M}$ of the dansyl peptide. The sample was excited at $290 \mathrm{~nm}$ and emission was monitored from $450 \mathrm{~nm}$ to $570 \mathrm{~nm}$. These spectra were corrected by subtracting the emission scan of S4 dansyl peptide with ATP and no Lon from the emission spectra of S4 dansyl peptide with Lon and ATP. An increase in dansyl fluorescence at $520 \mathrm{~nm}$ is observed with increasing concentrations of S4 peptide. Similar results were obtained with the S679W Lon mutant. 
Figure 2A

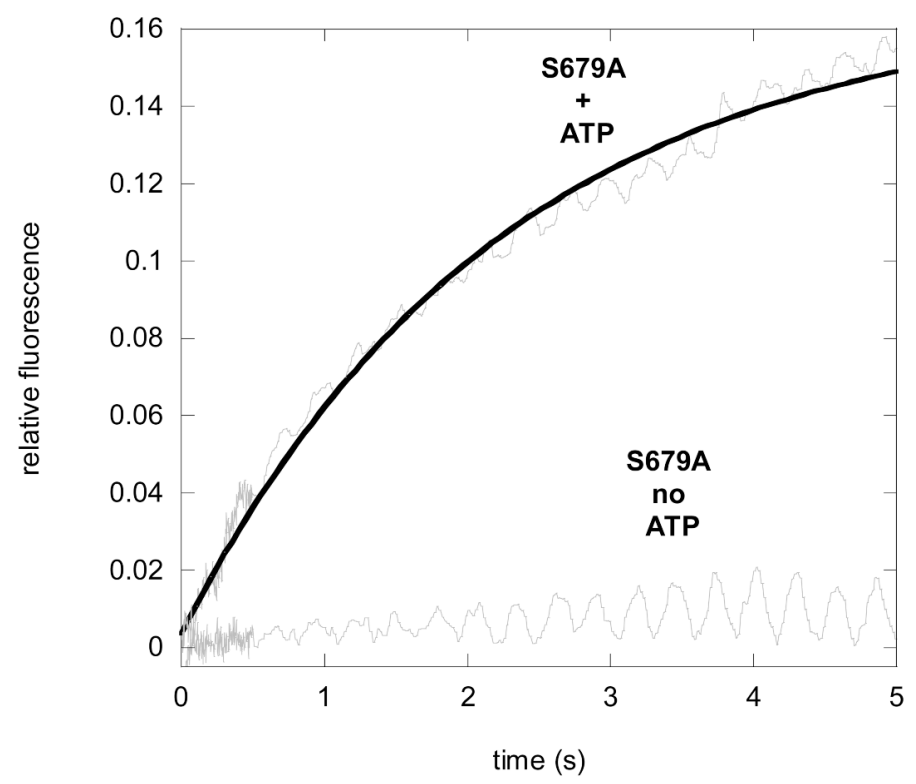

Figure 2B

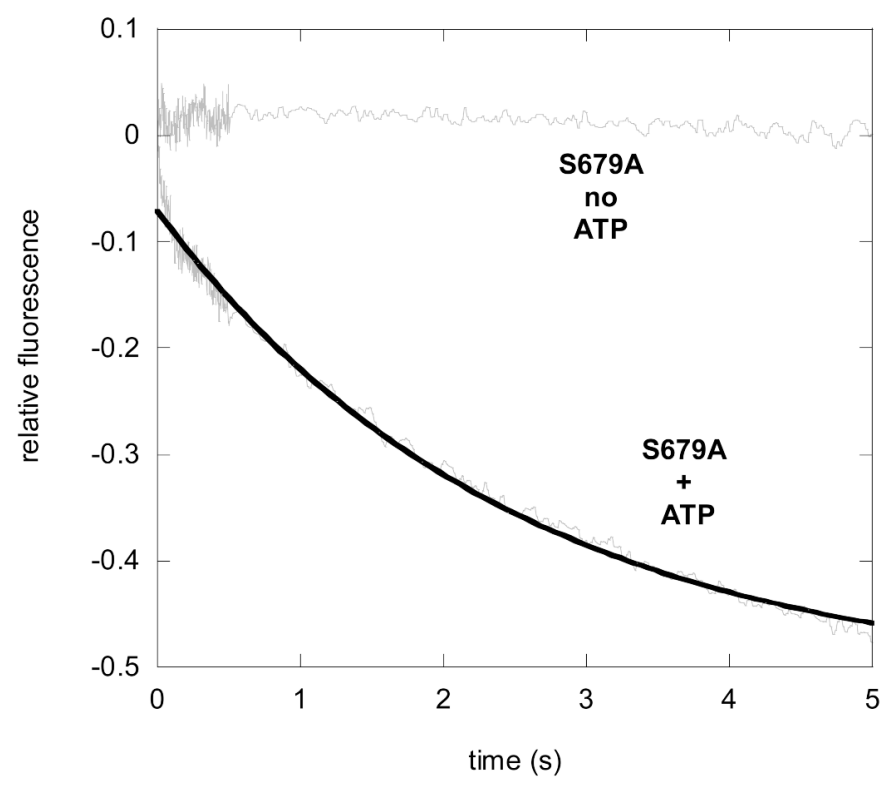

Figure 2.

Peptide binding to S679A can be monitored using the S4 dansyl peptide. The experimental time courses are shown in grey and the fitted curve is shown in black. The time courses with ATP were fit with eq 1 describing a single exponential. (A). Five micromolar S679A was incubated with $100 \mu \mathrm{M}$ S4 dansyl peptide and rapidly mixed with $100 \mu \mathrm{M}$ ATP. The reaction was excited at $290 \mathrm{~nm}$ and monitored using a $450 \mathrm{~nm}$ longpass filter to measure dansyl fluorescence. No changes in fluorescence were observed in the absence of ATP.

(B) The reactions described in Figure 2A were also monitored for changes in Trp fluorescence by excitation at $290 \mathrm{~nm}$ and detecting emission with a $340 \mathrm{~nm}$ bandpass filter. No changes in 
fluorescence were observed in the absence of ATP. Identical reaction time courses were obtained when S679A was rapidly mixed with S4 peptide pre-mixed with ATP. 


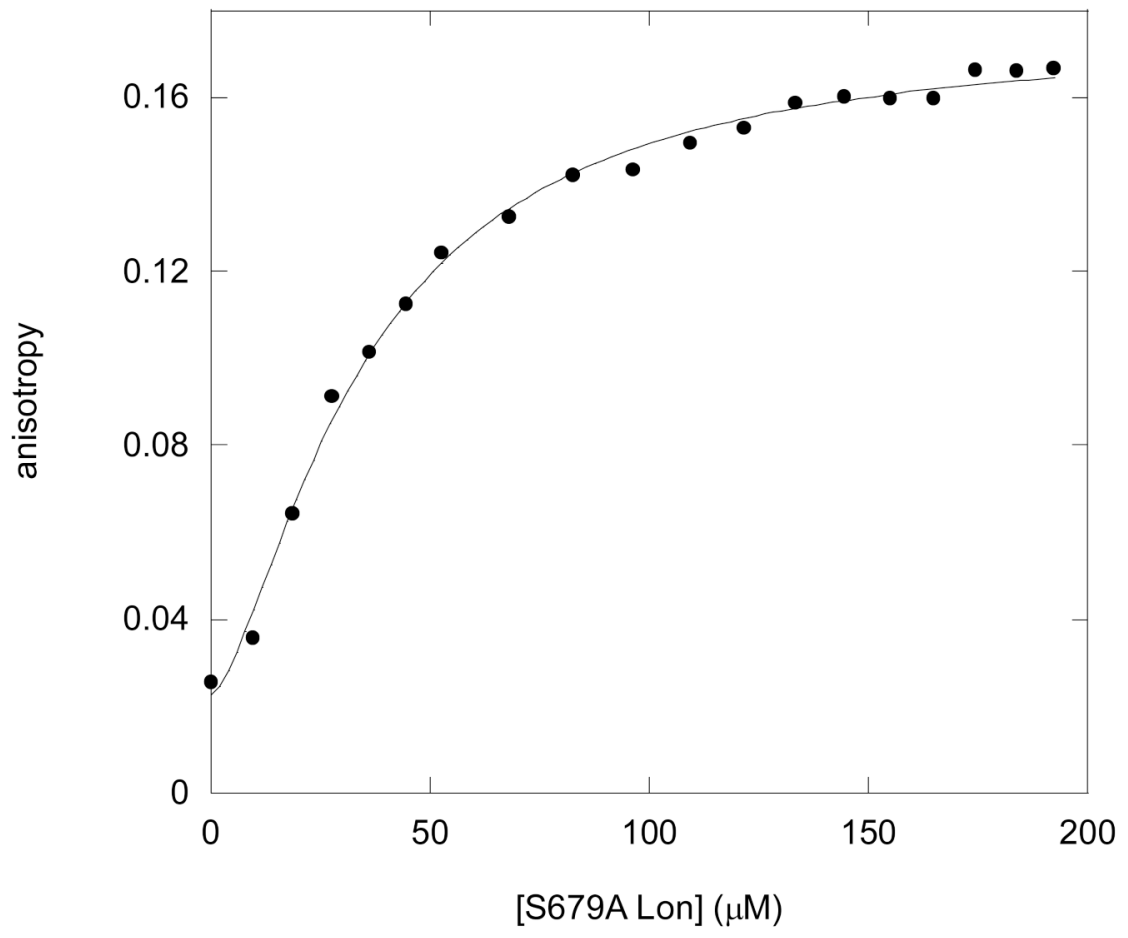

Figure 3.

Equilibrium binding of S4 dansyl peptide to S679A Lon can be measured using fluorescent anisotropy. Twenty micromolar S4 dansyl peptide was incubated with $1 \mathrm{mM}$ AMPPNP $(10 \times$ $\mathrm{K}_{\mathrm{d}}$, determined previously and reported in (36)) and changes in anisotropy were measured (excitation $340 \mathrm{~nm}$ emission $520 \mathrm{~nm}$ ) by titrating in S679A Lon $(0 \mu \mathrm{M}-192 \mu \mathrm{M})$. The data were fit with eq. 7 resulting in $\mathrm{K}_{\mathrm{d}}=35.2 \pm 18.6 \mu \mathrm{M}$ with a Hill coefficient (n) of $1.5 \pm 0.1$. The data shown are an average of 3 trials. Similar results were obtained in S679A and in the wild-type enzyme when nucleotide was omitted (see Results). 


\section{Figure 4A}

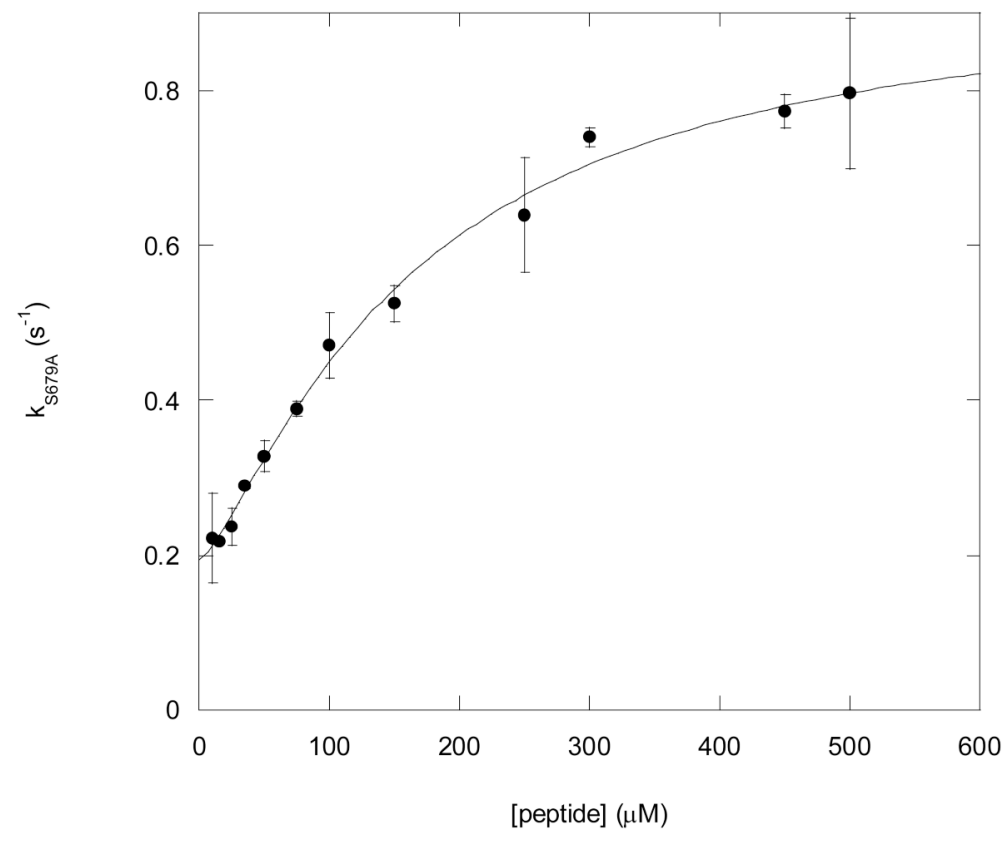

\section{Figure 4B}

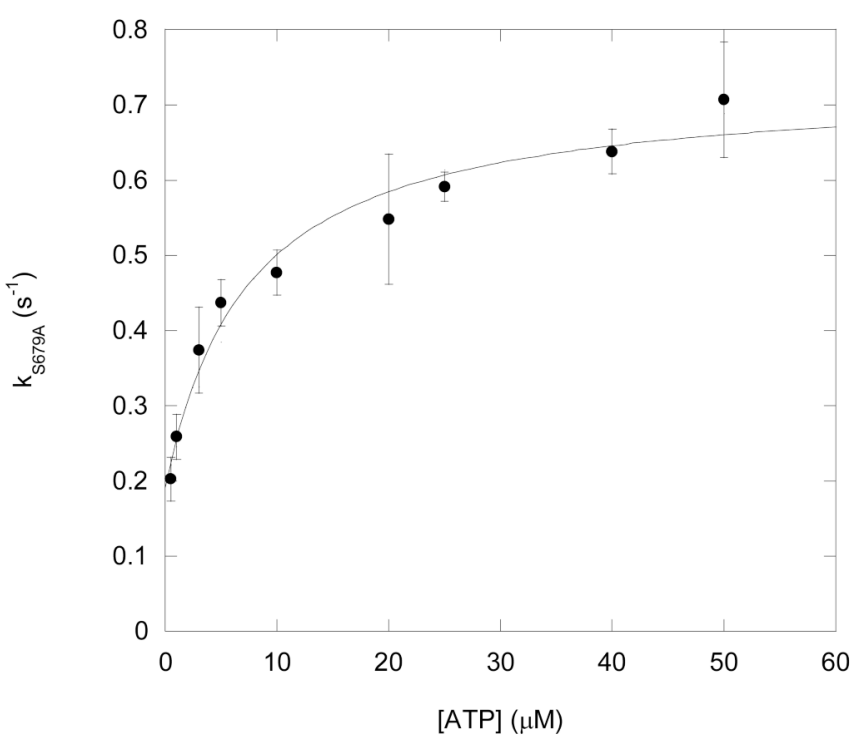

Figure 4.

S4 dansyl peptide binding to S679A is dependent on peptide and ATP. (A) Five micromolar S679A and varying concentrations of S4 dansyl peptide $(10,15,25,35,50,75,100,150,250$, 300,450 or $500 \mu \mathrm{M}$ ) was rapidly mixed with $100 \mu \mathrm{M}$ ATP. The time courses were fit with eq. 1 and the resulting rate constants are plotted as a function of the corresponding peptide concentration. The data in (A) were fit with eq 6 to yield a maximum $\mathrm{k}_{\mathrm{S} 679 \mathrm{~A}}=0.74 \pm 0.10$ $\mathrm{s}^{-1}, \mathrm{~K}_{\mathrm{d}}=164 \pm 35 \mu \mathrm{M}, \mathrm{k}_{\mathrm{rev}}=0.19 \pm 0.01 \mathrm{~s}^{-1}, \mathrm{n}=1.3 \pm 0.2$ (Table 2).

(B). Five micromolar S679A and $500 \mu \mathrm{M}\left(3 \times \mathrm{K}_{\mathrm{m}}\right) \mathrm{S} 4$ dansyl peptide was rapidly mixed with varying concentrations of $\operatorname{ATP}(0.5,1,3,5,10,25$ or $50 \mu \mathrm{M})$. The time courses were fit with eq. 1 and the resulting rate constants are plotted as a function of the corresponding ATP 
concentration. The data in $(\mathbf{B})$ were fit with eq 5 to yield a maximum $\mathrm{k}_{\mathrm{S} 679 \mathrm{~A}}=0.54 \pm 0.04$ $\mathrm{s}^{-1}, \mathrm{~K}_{\mathrm{d}}=7.4 \pm 2.5 \mu \mathrm{M}, \mathrm{k}_{\mathrm{rev}}=0.19 \pm 0.03 \mathrm{~s}^{-1}$ (Table 2). 


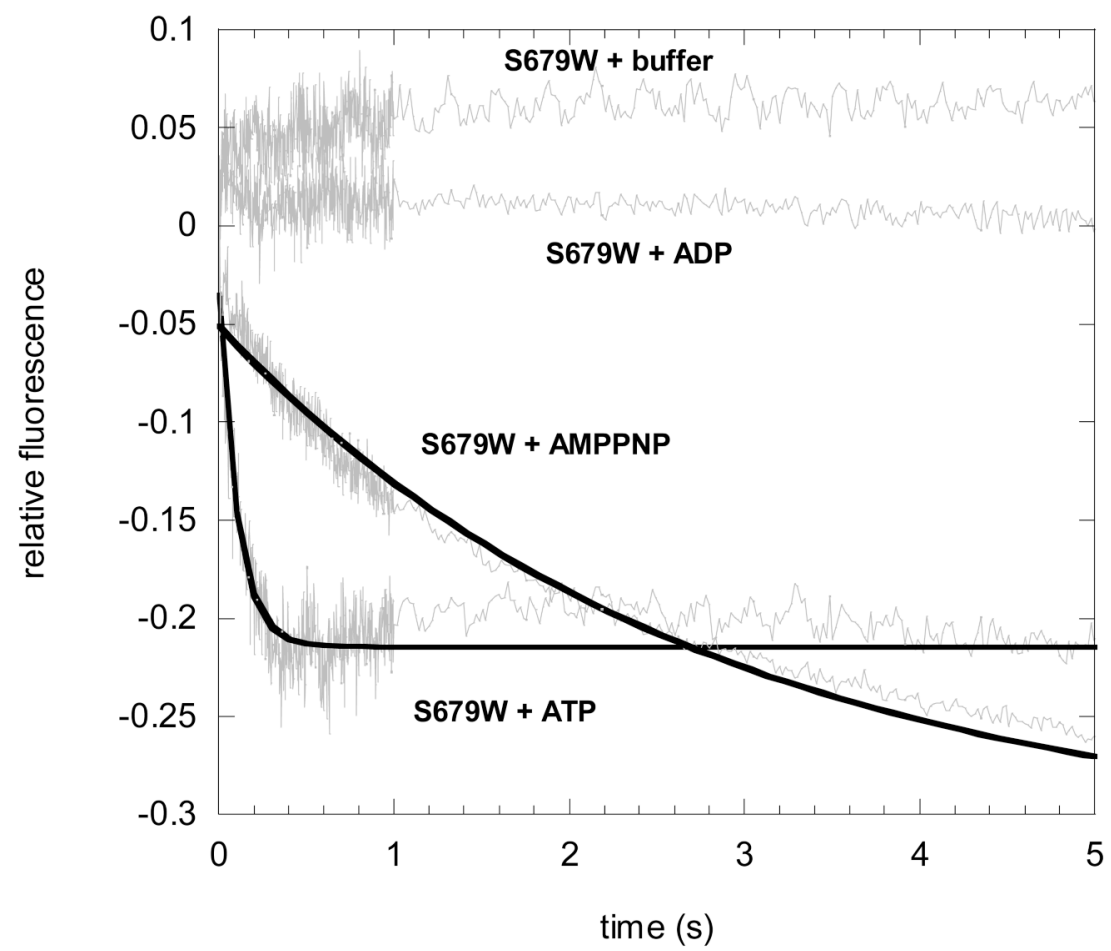

Figure 5.

Intrinsic tryptophan fluorescence can be used to measure a conformational change in S679W dependent on ATP and AMPPNP. No significant changes are observed with buffer or ADP. Five micromolar S679W was rapidly mixed with buffer, $100 \mu \mathrm{M}$ ATP, $100 \mu \mathrm{M}$ AMPPNP or $100 \mu \mathrm{M}$ ADP in a stopped-flow instrument. The reactions were excited at $290 \mathrm{~nm}$ and emission was detected using a 340 bandpass filter to detect Trp fluorescence. The reaction with ATP was fit with eq 1 describing a single exponential and the reaction with AMPPNP was fit with eq 2 describing a single exponential followed by a steady-state. The experimental time course is shown in grey and the fitted curve is shown in black. 
Figure 6 A

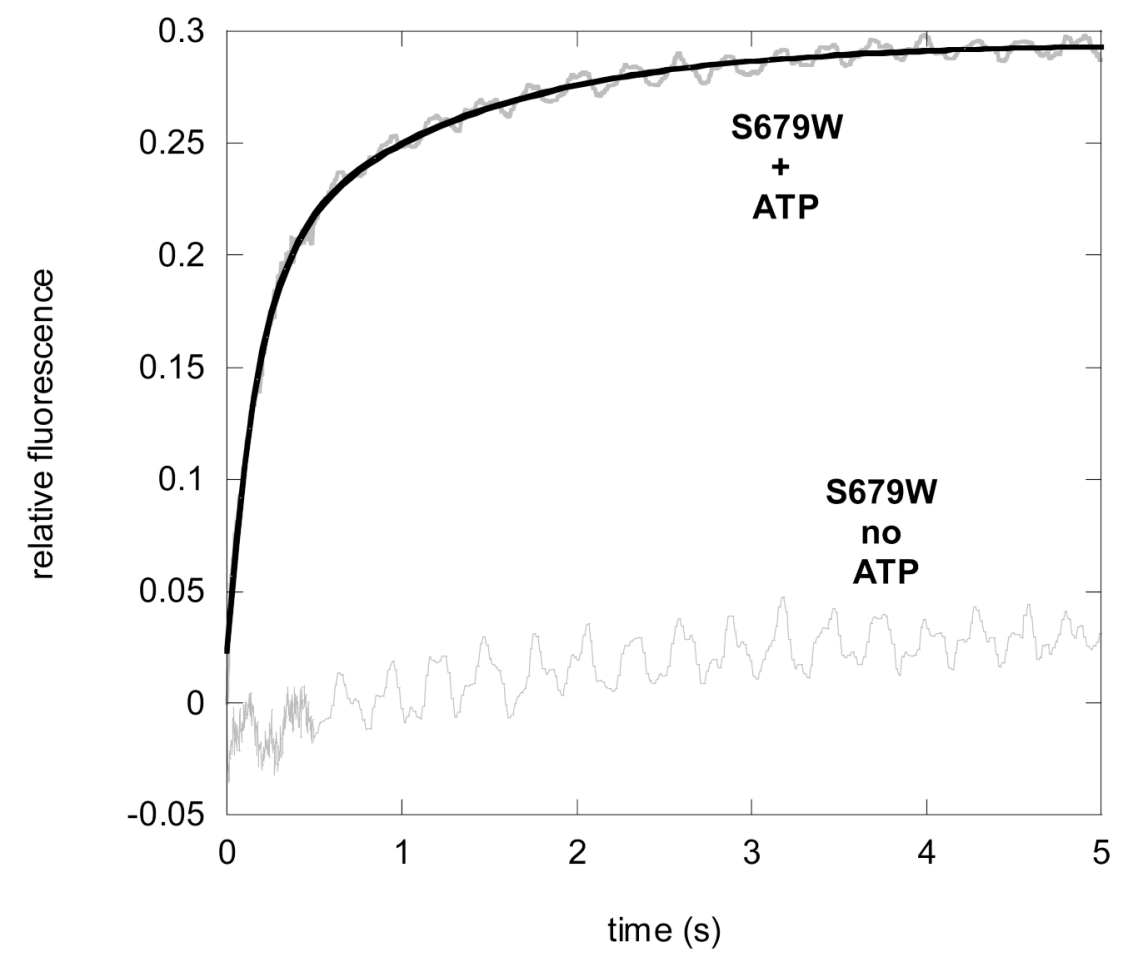

Figure 6B

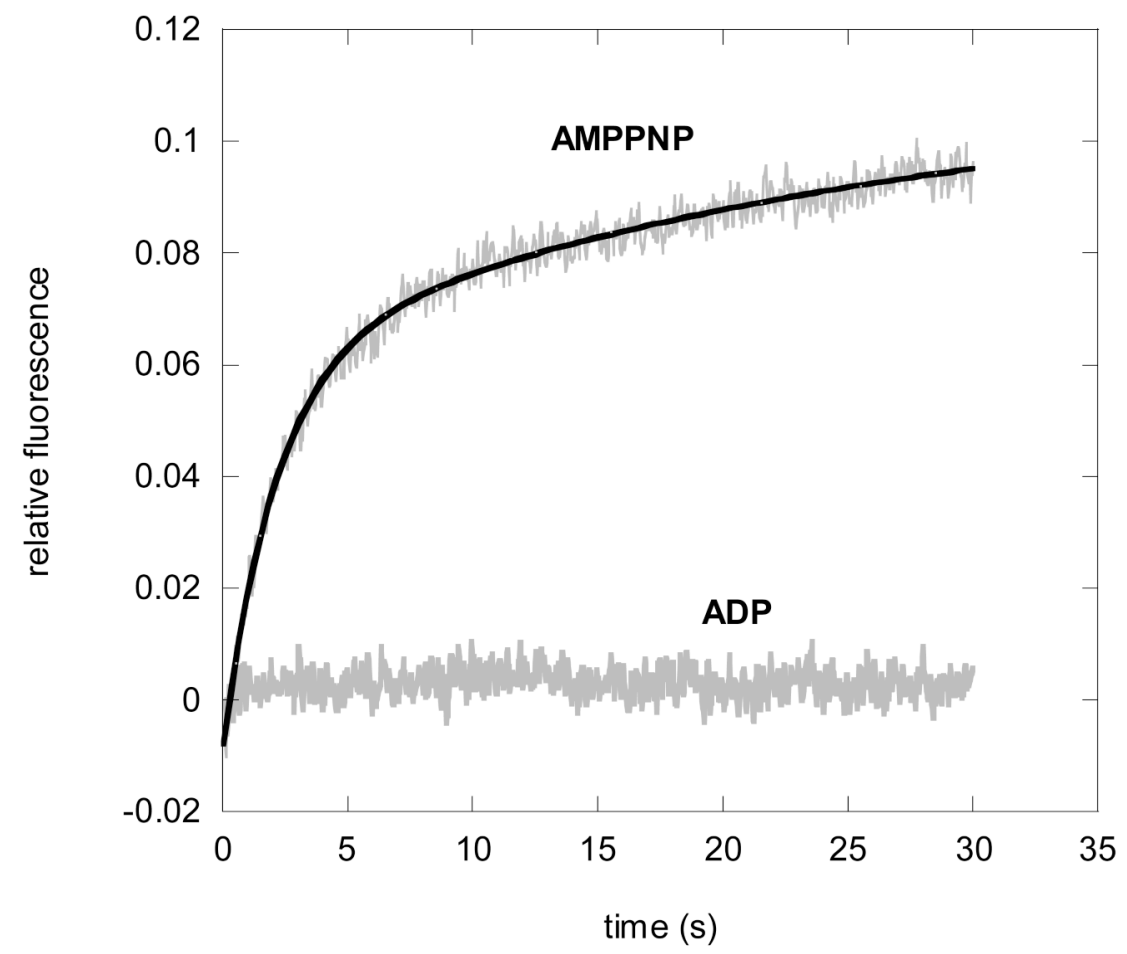

Biochemistry. Author manuscript; available in PMC 2008 November 27. 


\section{Figure 6.}

Peptide binding to S679W can be monitored using the S4 dansyl peptide. The experimental time courses are shown in grey and the fitted curve is shown in black. (A). Five micromolar S679W was preincubated with $100 \mu \mathrm{M} \mathrm{S} 4$ dansyl peptide and rapidly mixed with $100 \mu \mathrm{M}$ ATP. The reaction was excited at $290 \mathrm{~nm}$ and monitored using a $450 \mathrm{~nm}$ longpass filter to measure dansyl fluorescence. The time course with ATP was fit with eq 3 describing a double exponential. No changes in fluorescence were observed in the absence of ATP.

(B). Five micromolar S679W was preincubated with $100 \mu \mathrm{M} \mathrm{S4}$ dansyl peptide and rapidly mixed with $100 \mu \mathrm{M}$ AMPPNP. The reaction was excited at $290 \mathrm{~nm}$ and monitored using a 450 $\mathrm{nm}$ longpass filter to measure dansyl fluorescence. The time course with AMPPNP was fit with eq 3 describing a double exponential. AMPPNP does support binding, however at a rate slower

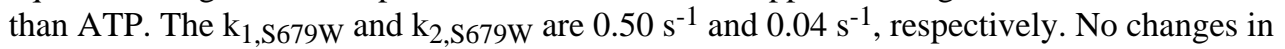
fluorescence were observed with ADP. 


\section{Figure 7A}

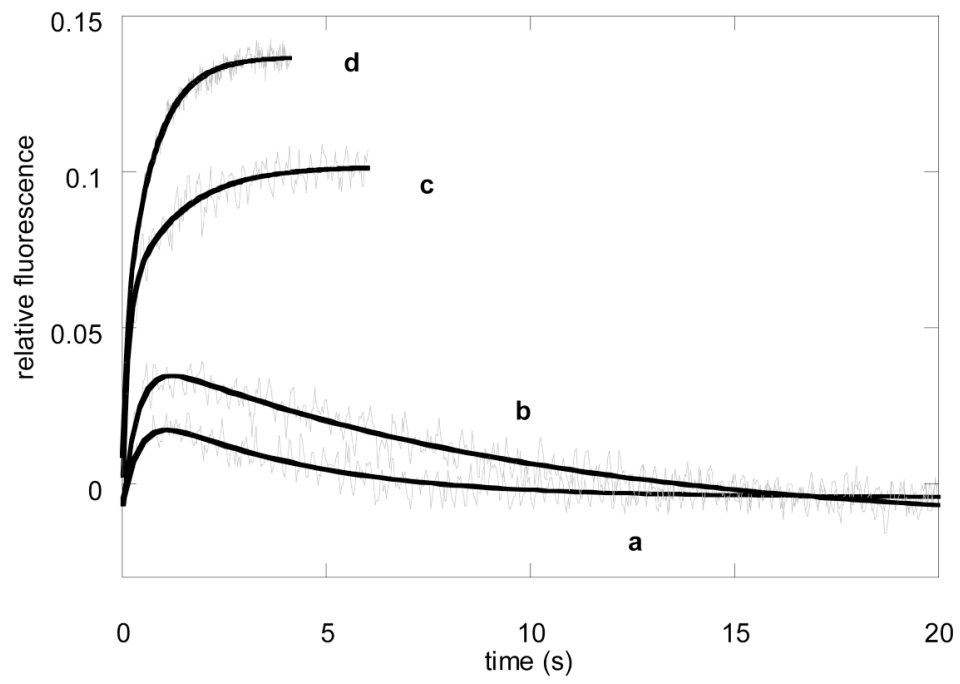

Figure 7B

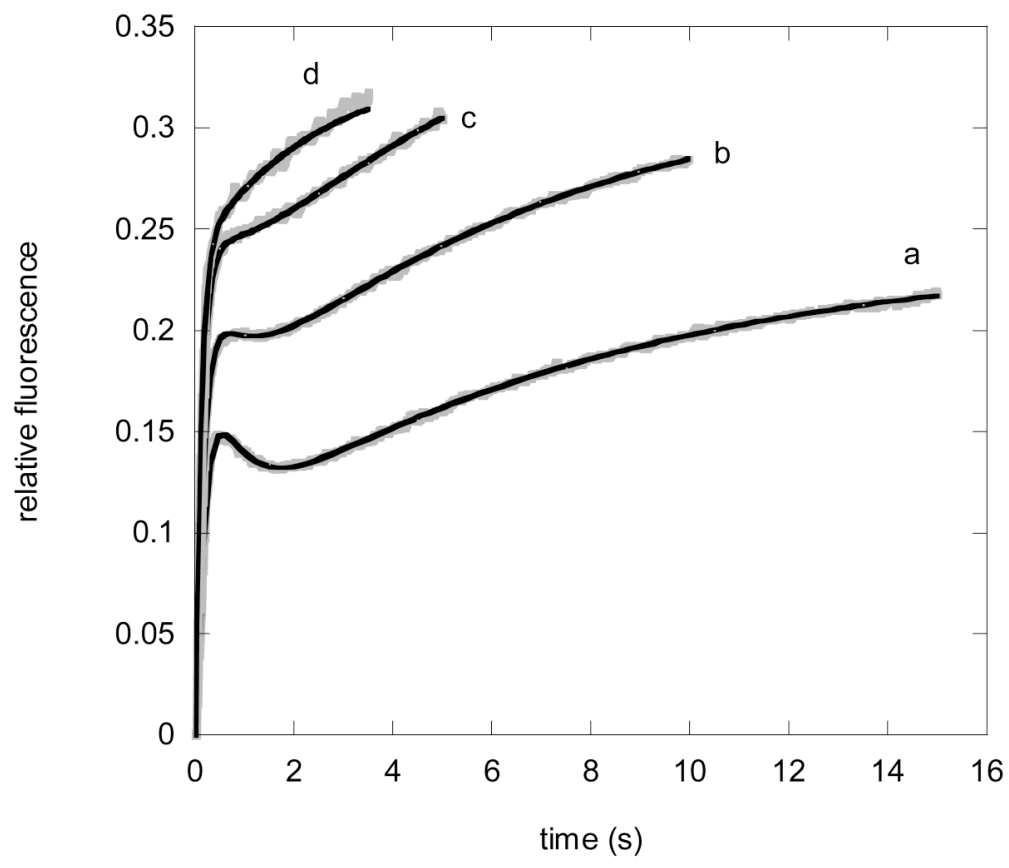

Figure 7.

Representative time courses for S679W interacting with the S4 dansyl peptide. All the reactions were excited at $290 \mathrm{~nm}$ and emission signals from the dansyl moiety in S4 were detected using a $450 \mathrm{~nm}$ long-pass filter. (A) Five micromolar S679W pre-incubated with $500 \mu \mathrm{M}$ S4 was rapidly mixed with (a) 0.5 ; (b) 1 ; (c) 5 and (d) $10 \mu \mathrm{M}$ ATP in a stopped flow apparatus. All the time courses were best fit with eq 3 describing a double exponential. The experimental time courses are shown in grey and the fitted curve is shown in black. At $<5 \mu \mathrm{M}$ ATP, the second phase of the time courses display negative changes in fluorescence whereas in the time courses measured at $\geq 5 \mu \mathrm{M}$ ATP, the overall changes in fluorescence were positive. 
(B) Five micromolar S679W pre-incubated with (a) 25; (b) 50; (c) 100 and (d) $500 \mu \mathrm{M} \mathrm{S} 4$ peptide were rapidly mixed with $100 \mu \mathrm{M}$ ATP in a stopped-flow apparatus. The experimental time courses are shown in grey and the fitted curve is shown in black. The sub $\mathrm{K}_{\mathrm{d}}$ levels of S4 $(25$, and $50 \mu \mathrm{M})$ were fit with eq. 4 (triple exponential). The 100 and $500 \mu \mathrm{M} \mathrm{S} 4$ time courses were fit with eq 3 (double exponential equation). 
Figure 8A

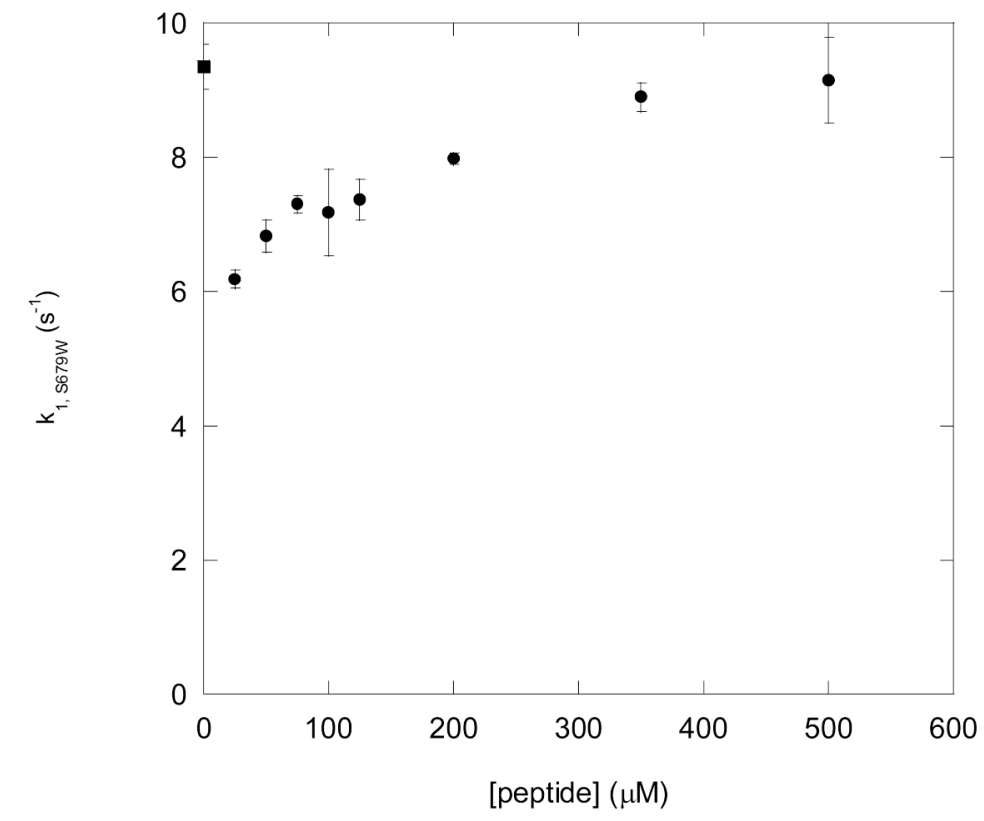

Figure 8B

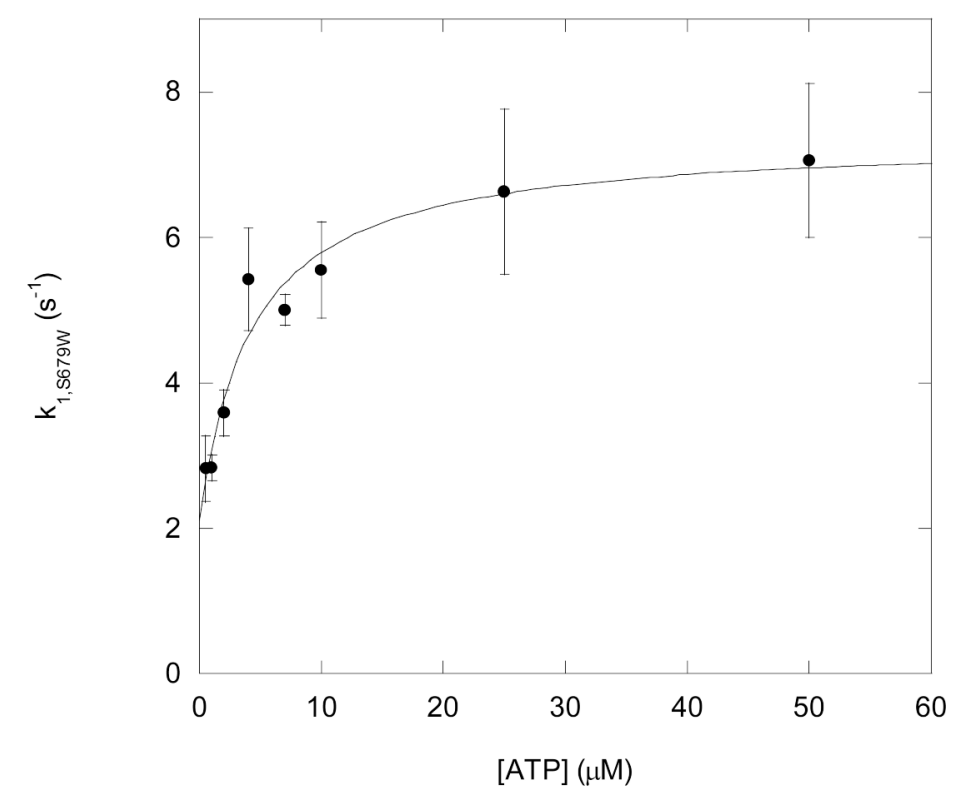

Biochemistry. Author manuscript; available in PMC 2008 November 27. 
Figure 8C.

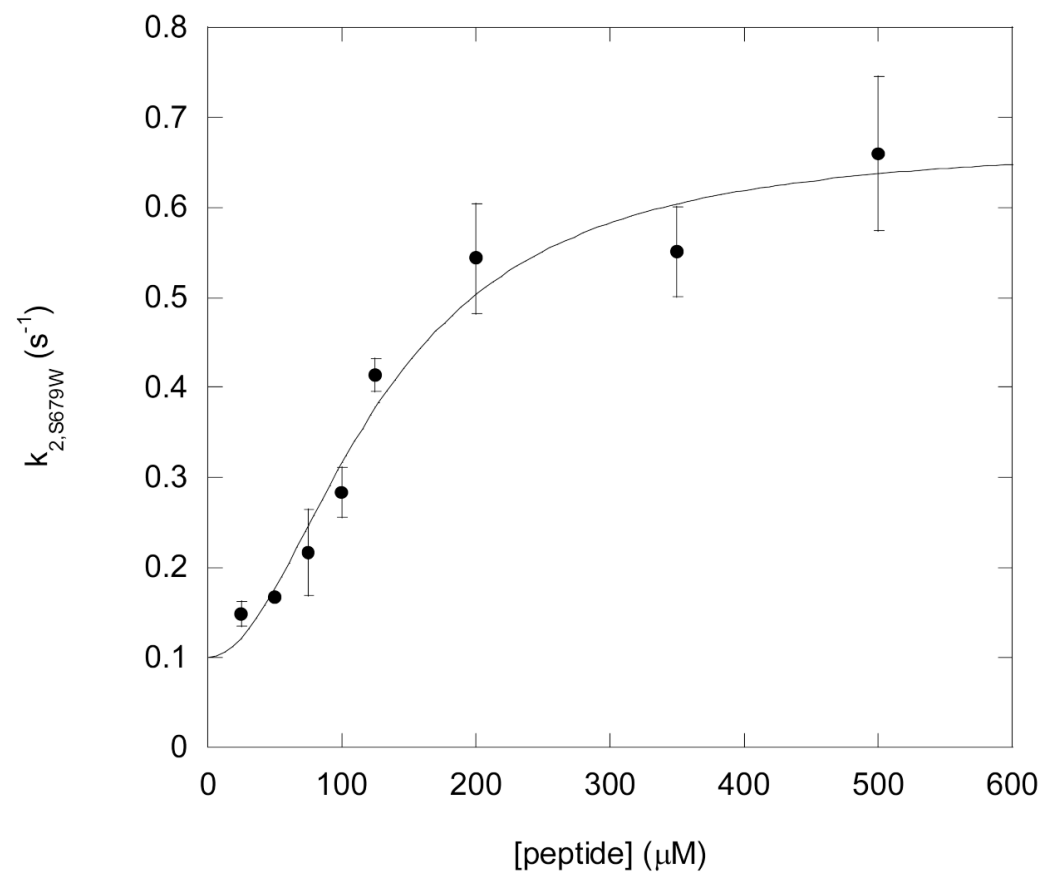

Figure 8D.

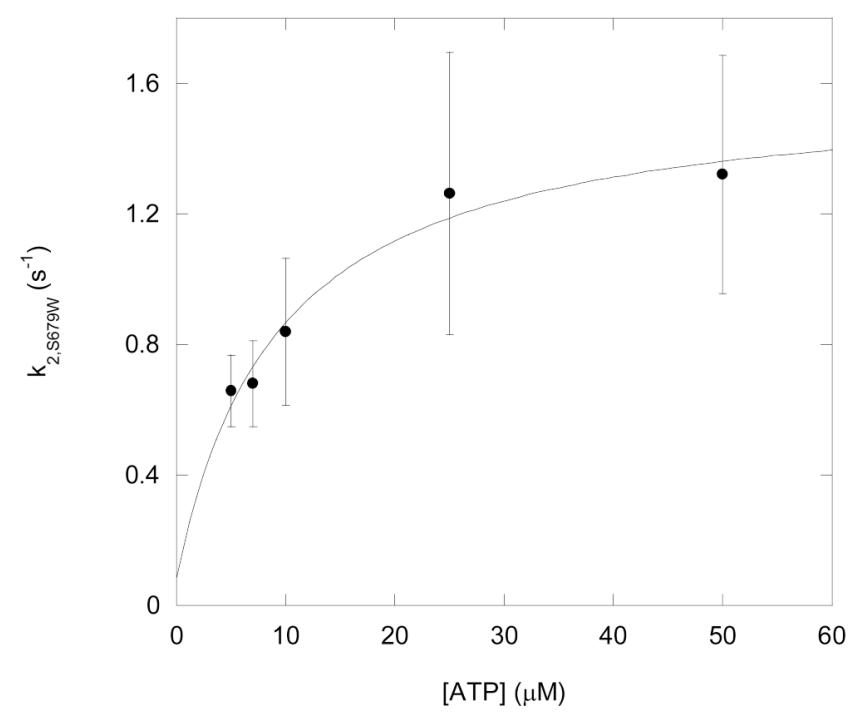

Figure 8.

In S679W Lon the first phase is dependent on nucleotide only and the second phase is dependent

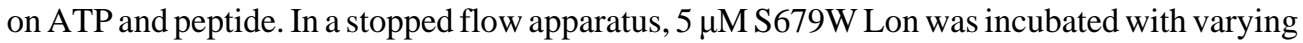
concentrations of S4 dansyl peptide $(25,50,75,100,125,200,350$ or $500 \mu \mathrm{M})$ and rapidly mixed with $100 \mu \mathrm{M}$ ATP or $5 \mu \mathrm{M}$ S679W Lon was incubated with $500 \mu \mathrm{M}$ S4 dansyl peptide and rapidly mixed with varying concentrations of $\operatorname{ATP}(0.5,1,2,4,7,10,25$ or $50 \mu \mathrm{M})$. The resulting time courses were fit with eq 3 or eq 4 and the resulting rate constants $\left(\mathrm{k}_{1, \mathrm{~S} 679 \mathrm{~W}}\right.$ and $\mathrm{k}_{2, \mathrm{~S} 679 \mathrm{~W})}$ are shown as a function of substrate concentration. (A) $\mathrm{k}_{1, \mathrm{~S} 679 \mathrm{~W}}=7.6 \pm 1.0 \mathrm{~s}^{-1}$ and is independent of peptide concentration. The $0 \mu \mathrm{M} \mathrm{S} 4$ peptide data point (-) was obtained by fitting the time course shown in Figure $5(\mathrm{~S} 679 \mathrm{~W}+\mathrm{ATP})$ to eq 1 to yield $\mathrm{k}_{1, \mathrm{~S} 679 \mathrm{~W}}=9.35 \pm$ 
$0.34 \mathrm{~s}^{-1}$. (B) $\mathrm{k}_{1, \mathrm{~S} 679 \mathrm{~W}}=5.3 \pm 0.6 \mathrm{~s}^{-1}$ is dependent on ATP concentration, $\mathrm{K}_{\mathrm{d}}=4.3 \pm 1.9 \mu \mathrm{M}$,

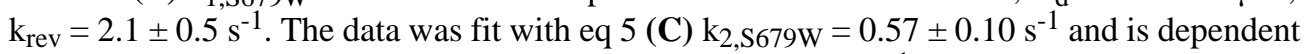
on peptide concentration, $\mathrm{K}_{\mathrm{d}}=157 \pm 8 \mu \mathrm{M}, \mathrm{k}_{\mathrm{rev}}=0.10 \pm 0.01 \mathrm{~s}^{-1}, \mathrm{n}=1.9 \pm 0.1$. The data was

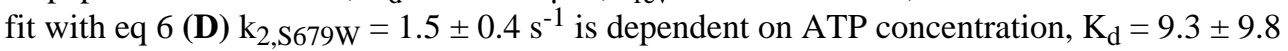
$\mu \mathrm{M}$. The data was fit with eq 5 . All the kinetic parameters are summarized in Table 2 . 


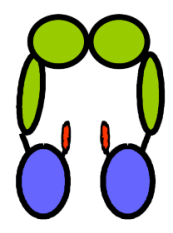

(I)

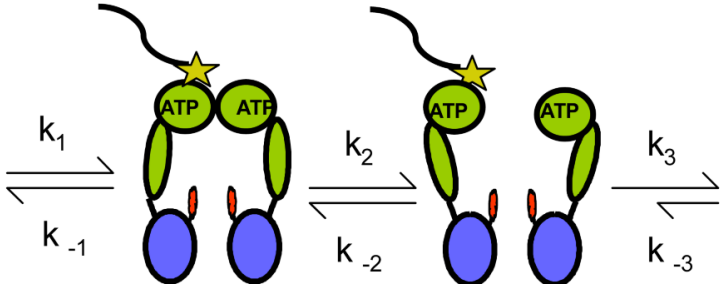

(II)

(III)

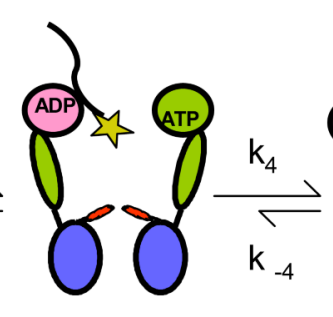

(IV)

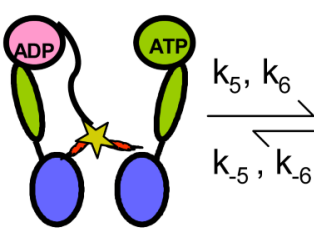

(V)

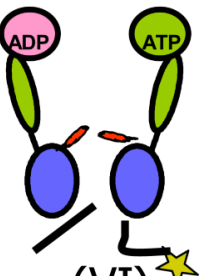

(VI)

$$
\begin{aligned}
& \mathrm{k}_{1}=\mathrm{k}_{\text {on,ATP }} \\
& \mathrm{k}_{2}=\mathrm{k}_{\mathrm{NTP}} \\
& \mathrm{k}_{3}=\mathrm{k}_{\mathbf{1 , S 6 7 9 w}} \sim \mathrm{k}_{\text {burst,ATP }} \\
& \mathrm{k}_{4}=\mathrm{k}_{\text {S679A }} \sim \mathrm{k}_{\mathbf{2 , S 6 7 9 w}} \sim \mathrm{k}_{\mathrm{lag}} \\
& \mathrm{k}_{5}=\text { peptide hydrolysis } \\
& \mathrm{k}_{6}=\text { product release }
\end{aligned}
$$

$\mathrm{k}_{-1}=\mathrm{k}_{\text {off,ATP }}$

$\mathrm{k}_{-2}=$ reverse of NTP conformational change

$\mathrm{k}_{-3}=\mathbf{k}_{\text {rev }}$$$
\mathrm{k}_{-4}=\mathbf{k}_{\text {rev }}
$$$$
\mathrm{k}_{-5}=\text { reverse of peptide hydrolysis }
$$$$
\mathrm{k}_{-6}=\text { reverse of product release }
$$

\section{Figure 9.}

Proposed mechanism for peptide hydrolysis. The enzyme is shown as a dimer instead of a hexamer for simplicity. The ATPase and SSD (sustrate sensor and discriminatory) domains are shown in green, the protease domain is shown in blue and the active site serine is shown in red. (I) Free enzyme. (II, step 1) ATP and peptide bind in a random order. (III, step 2) A conformational change resulting from nucleotide binding. (IV, step 3) Allosteric activation of the proteolytic site accompanied by ATP hydrolysis. (V, step 4). A slow peptide delivery/ translocation event. (VI, step 5) Peptide hydrolysis and product release. The rate constants in bold are measured in this study. All other rate constants have been published previously by our lab. 
1

$$
\text { Lon }+ \text { peptide } \stackrel{\mathrm{k}_{\mathrm{on}}}{\underset{\mathrm{k}_{\text {off }}}{\rightleftharpoons}} \text { Lon:peptide } \underset{\mathrm{k}_{\mathrm{S} 679 \mathrm{~A}, \text { rev }}}{\stackrel{\mathrm{k}_{\mathrm{S} 679 \mathrm{~A}}}{\rightleftharpoons}} \text { Lon*:peptide }
$$

\section{Scheme 1.}

Peptide binding steps measured using the S679A Lon mutant

1. An initial peptide binding event independent of nucleotide. This step is measured using equilibrium fluorescence anisotropy

2. A conformational change step following initial binding that requires nucleotide. This step is measured using stopped- flow kinetic techniques

**It should be noted that ATP binds to Lon independent of peptide. The Lon*:peptide complex contains ATP 


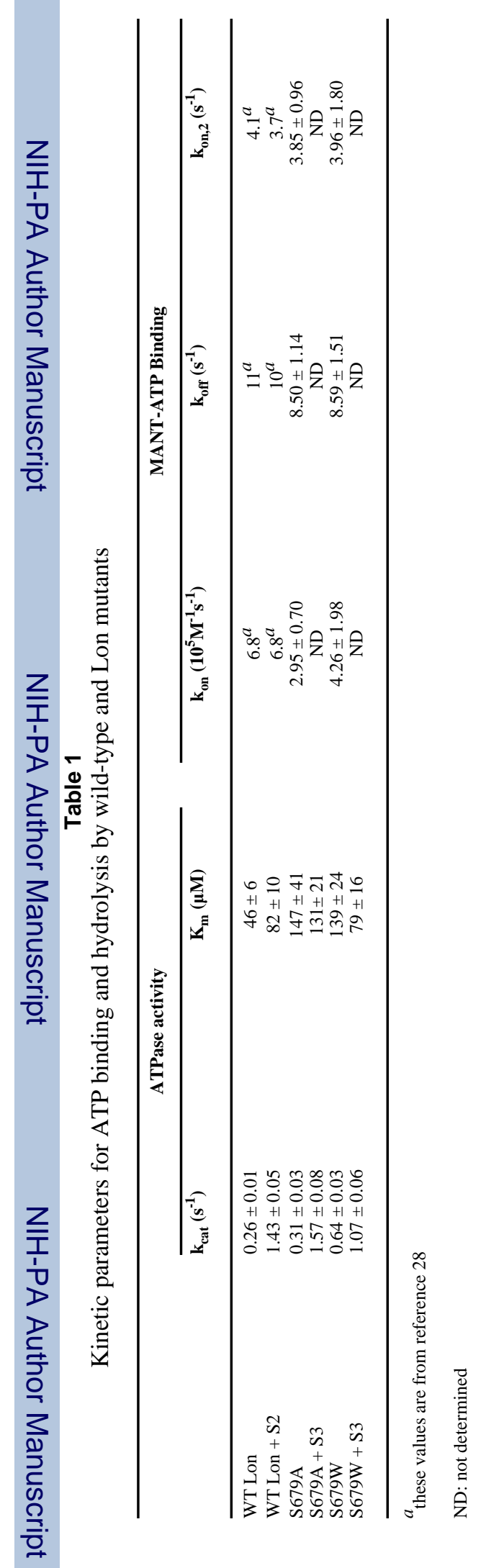




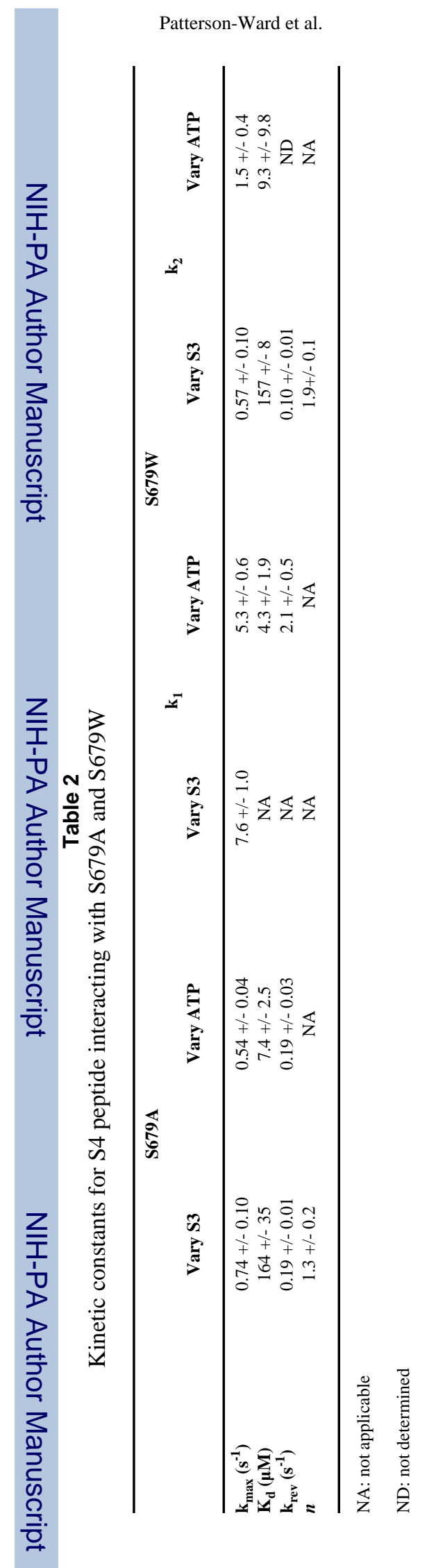

Biochemistry. Author manuscript; available in PMC 2008 November 27. 